\title{
Optimal Supply Diversification Strategy under Supply Disruption
}

\author{
Xiaomeng Luo $\mathbb{D}$ and Jia Ren $(1)$ \\ School of Business Administration, Southwestern University of Finance and Economics, Chengdu, Sichuan 611130, China \\ Correspondence should be addressed to Xiaomeng Luo; luoxm@swufe.edu.cn
}

Received 9 January 2020; Revised 16 April 2020; Accepted 18 April 2020; Published 13 August 2020

Guest Editor: Davide Castellano

Copyright (c) 2020 Xiaomeng Luo and Jia Ren. This is an open access article distributed under the Creative Commons Attribution License, which permits unrestricted use, distribution, and reproduction in any medium, provided the original work is properly cited.

\begin{abstract}
When a disruption caused by human or environmental accident occurs in production systems, it may cause a shortage of the supply, and thus the buyers' procurement behaviors will be influenced. This paper studies a supply chain comprised of a buyer and two types of suppliers: one is cheap but unreliable and the other is reliable but expensive. If there is a major disruption, the unreliable supplier may not be able to fully satisfy the buyer's order, despite the fact that it exerts additional effort to rebuild capacity; at the same time, the reliable supplier cannot fulfill extra orders from the buyer due to capacity constraints. In this way, the buyer should strategically allocate its order between the two types of suppliers by offering different contracts at the very beginning, and then the unreliable supplier chooses its optimal restoration effort according to the contract if a disruption occurs. The model is built based on the real-life cases such as Walmart and Apple such that it is the buyer who determines the wholesale price of the unreliable supplier's products. The results show the optimal contracts provided by the buyer under different circumstances, which aims to help managers design their contracts under disruption risks to maximize the company's profit.
\end{abstract}

\section{Introduction}

It is common to observe a variety of disruptions occurring in global supply chain, and thus firms are exposed to risks and uncertainties [1]. The disruption can be attributed to various factors such as natural disasters, financial bankruptcy, government policy, and human factors. When a disruption happens, firms would be quite passive if they did not prepare backup plans. For example, two deadly earthquakes that happened in Southern Japan halted Sony's production of image sensors in 2016. This affected the procurement of its major customers, and, thus, for instance, Apple had to postpone the supply of its new iPhone while Samsung shifted to alternative suppliers at a much higher price although its production process is not affected ("Japan Quakes Close Sony Factory Making Key iPhone Part," Fortune, 16 April, 2016, https:// fortune.com/2016/04/16/japan-quakes-disrupt-sony-imagesensors-apple-iphones/, accessed on January 2020). More recently, a series of actions have been taken by Apple to mitigate the effects of possible disruptions: execs from Apple, together with representatives from Google, Microsoft, and Amazon, visited Korea to ensure consistent supplies of critical chips, which might be affected by the trade war between Japan and Korea; and, considering the disruption risk caused by the US-China trade war, Apple has planned to shift $15 \%$ to $30 \%$ production out of China to reduce its dependence on Chinese suppliers ("Apple Execs Rush to Samsung in Korea Fearing Disruption in iPhone Chip Supplies," iGeeksBlog, 20 July, 2019, https://www.igeeksblog.com/apple-execs-rush-samsungiphone-chip-supplies-135428/, accessed on January 2020).

Although it is more efficient to procure from a single supplier aiming at developing long-term relationship, firms tend to diversify their sources to prevent supply disruption in practice. A classic case regarding two famous mobile communication producers shows the benefits brought by diversifying procurement sources. In March 2000, a Philips Semiconductor plant has been shut down due to a sudden fire caused by lightning in Albuquerque, New Mexico, for six weeks. This leads to a shortage of components for both Ericsson and Nokia, but the situations of the two companies are very different. Although Nokia has lost all of the supply from the Philips plant, it was able to source from alternative suppliers by temporarily increasing their production and thus suffered little financial loss at last. However, Ericsson 
did not have backup suppliers to shift supply, so it eventually lost at least 400 million dollars in potential revenue [2]. To adopt multisource strategy, some critical decisions need to be determined by firms at the very beginning, such as how many suppliers to choose and how many quantities to procure from each of them. The common practice is to source the majority of products from one or two major suppliers which provide favorable terms and the minority from other small suppliers, just as Samsung and Nokia do.

The fact is if firms are sufficiently powerful, they can procure products at the prices they are pleased of. For example, more than 450 US companies competed to provide 750 products in the stores of Walmart nationwide in 2016, and only some of them won the chance to get into the stores. The unequal power in the supply and demand relationship between Walmart and its suppliers adds bargaining power to Walmart. Thus, it is Walmart's decision to set the final wholesale price based on the cost structure of the product, which requires the suppliers to eliminate excess costs ("Amy Feldman, "What It Takes To Sell To Walmart: A Senior Buyer Tells All," Forbes, 11 May, https://www.forbes.com/ sites/amyfeldman/2017/05/11/what-it-takes-to-sell-to-walmarta-senior-buyer-tells-all/\#25ef71e5352b, accessed on January 2020). Other large companies such as Costco, Amazon, and Apple are similar to Walmart when bargaining with their suppliers on price. The suppliers can choose to accept the prices offered by those big names or they can leave. Most suppliers will choose to stay considering the large volume and reputation provided by big companies. Thus, the procurement decisions of those companies become how many suppliers to choose and which wholesale price and order quantity to provide to each of the suppliers.

Based on the above background, this paper aims to study the optimal procurement strategy of a powerful firm (referred to as "buyer"). Basically, the buyer can source from two types of suppliers, reliable but expensive ones and unreliable ones which may suffer production disruptions. The buyer has to decide which type of suppliers to partner with and how many quantities to procure at what wholesale price. In all, there are three possible strategies: procuring from the reliable suppliers only, sourcing from the unreliable ones only, and ordering from both types of suppliers. The buyer chooses the best answer by making a tradeoff between the profit and the risk. We are interested in which strategy would be the optimal choice for the buyer when the risk of production disruption exists. The remainder of this paper is organized as follows: Section 2 summarizes the relevant literature, Section 2 provides the model description, and optimal results are given in Section 4 . Section 5 provides a numerical study. Conclusion is presented in Section 6 .

\section{Literature Review}

The management of supply disruption has long been an interesting topic for both researchers and practitioners in the Operations Management field. We may refer to Vakharia and Yenipazarli [3] for an excellent review of relevant literature, Snyder et al. [4] for a summary for OR/MS models used in the study of supply chain disruption, and Ivanov et al. [5] for quantitative tools used in supply chain disruption recovery.

To fight against supply disruption, which is modeled as an all-or-nothing yield model, supply diversification is a useful strategy $[6,7]$. Other operational tools include multiple sourcing $[6,8]$, improvement in reliability and process (Liu et al. [9] and Wang et al. [10]), and cost-sharing mechanism [11]. Iyer et al. (2005) studied the supplier's optimal contract structure and explored the impact of an alternate supplier in a supply chain consisting of a monopolist supplier and multiple buyers. By conducting a detailed study, Tomlin [12] considers firm characteristics such as risk tolerance and supplier characteristics such as percentage uptime, disruption length, capacity, and flexibility to study the supply disruption management problem. They provide various strategies adopted by buyers to manage supply disruption risk, including investment in inventory, cooperation with multiple suppliers, and preparation for backup orders to alternative suppliers. Hu et al. [13] study how a buyer can use incentive mechanisms to motivate a supplier's investment in capacity restoration and compare this approach with the traditional approach of diversifying part of the order to an expensive but reliable supplier. Chen et al. [14] compare two incentive mechanisms, i.e., providing financial subsidy and adjusting the wholesale price(namely, direct and indirect contract, respectively) and study their effects on the supplier's investment behavior.

A lot of factors are involved in the study for supply disruption. Gupta et al. [15] consider competition in the buyer level and find that both supply disruption and procurement times will affect the buyers' procurement decisions. Ray and Jenamani [16] analyze the uncertainty from both the supply side and the demand side, providing the optimal order allocation to hedge against supply disruption risk. Besides all-or-nothing supply, Tang et al. [17] involve partial disruption and find that subsidy is preferred in all-ornothing setting, while both subsidy and order inflation are optimal in partial disruption setting. Tsai [18] proposes a dynamic sourcing strategy that helps managers determine the optimal number of suppliers required in different scenarios. Based on a multitier supply chain structure, Ang et al. [19] explore the interactions between the manufacturer and suppliers and show that the degree of overlap in the supply chain may impact the optimal strategies of both manufacturer and tier 1 supplier. A series of articles analyze the supply chain coordination under supply disruption risks [20-22]. Specifically, Sawik [23] provides the stochastic and deterministic approaches to coordinate the supply chain and finds that the stochastic approach offers a more diversified supply portfolio which helps deal with a variety of scenarios.

Although managers know clearly the impact of supply chain disruptions, they actually have done little to prevent the incidents and corresponding effects [24]. Chopra and Sodhi [25] thus remind managers to notice the disruption risk when they pursue cost efficiency by providing feasible advices on real actions. Based on the real situation of the Chinese dairy market, $\mathrm{He}$ et al. [26] explore the optimal ordering strategy for a retailer who can source from a local supplier and an oversea supplier under supply disruption. 
With the help of real-option pricing methodology and actuarial techniques, they help managers to make decisions on procurement. Our model studies a supply chain composed of one buyer and two suppliers, and there are three options for buyer to choose: the first one is ordering from the reliable supplier only, the second one is ordering from the unreliable supplier only, and the third one is ordering from both of them. It is obvious that the first one is more expensive and the second one is more risky, and thus the intermediate choice not only avoids some risk but also reduces cost. The main features of our proposed model are the focus on supplier's restoration effort after disruption and buyer's order allocation strategy and pricing strategy.

\section{Model Description}

We consider a supply chain that consists of a buyer and two suppliers: one is reliable supplier and the other one is unreliable supplier. For simplicity, we assume that the market demand $d$ and retail price $p$ are fixed and given. We further assume that the original capacity of either supplier is enough to cover the market demand. Specifically, the reliable supplier can fully satisfy the buyer's order, and the unreliable supplier also can if there is no disruption. Note that once the order has been offered to the reliable supplier, no replenishment order can be placed later if the unreliable supplier suffers disruption. To better model the practice in the real world, we assume that the wholesale price of the reliable supplier's product is deterministic, which is determined by the market, while the wholesale price of the unreliable supplier's product is decided by the buyer since the buyer has power towards the unreliable supplier. Thus, the buyer has to decide an order allocation between the two suppliers and the wholesale price from the unreliable supplier to maximize its own profit.

For the unreliable supplier, we use $\left(q_{u}, w_{u}\right)$ to denote the contract offered by the buyer. Following Anupindi and Akella [6] and Gurnani et al. [10], we assume that the risk of disruption is dichotomous (all or nothing), which means that the unreliable supplier may lose all of its capacity if there is an unexpected disruption. There is no disruption with probability $\beta$ and disruption occurs with probability $1-\beta$. When disruption happens, the unreliable supplier has to decide whether and how much costly effort to exert to rebuild capacity. The amount of restored capacity is proportional to the supplier's effort level $e$; that is, with effort $e$, the restored capacity is $\alpha e$, where $\alpha$ is a deterministic factor and we further assume that $\alpha=1$. Restoration effort incurs a cost determined by a convex and increasing function $C_{R}(e)$, representing the diminishing return of effort on capacity recovery [27]. The production cost of either supplier is normalized to 0 , and the unit production cost of the unreliable supplier after disruption is assumed to be $c_{d}$.

For the reliable supplier, we use $\left(q_{r}, w_{r}\right)$ to represent the long-term contract provided by the buyer, where $w_{r}$ is deterministic and is exogenously given. We assume that the reliable supplier has unlimited capacity of satisfying the order but cannot afford any more orders if the unreliable supplier is not able to meet the order. To ignore the trivial case, we assume $w_{r}>w_{u}$.
The buyer can source from two suppliers to reduce the risk of the disruption and save cost through two contracts: one is a long-term contract $\left(q_{r}, w_{r}\right)$ for the reliable supplier and the other one is $\left(q_{u}, w_{u}\right)$ for the unreliable supplier. The buyer's problem is whether to source from two suppliers and how many to order from either. Note that the buyer does not offer any extra incentive to the unreliable supplier for restoring capacity if a disruption occurs. This is because the buyer can still receive a part of the order from the reliable supplier even if the unreliable supplier suffers disruption and does not exert any restoration effort. If there is a disruption, the sequence of the events is shown in Figure 1.

\section{Equilibrium Analysis}

Our goal is to find the optimal restoration effort exerted by the unreliable supplier, $e^{*}$, the optimal order quantities, $q_{u}^{*}$ and $q_{r}^{*}$, and the optimal wholesale price offered by the buyer to the unreliable supplier, $w_{u}^{*}$.

4.1. Optimal Strategy of Unreliable Supplier. If a disruption occurs, the unreliable supplier exerts restoration effort $e$ based on the contract $\left(q_{u}, w_{u}\right)$. For analytical tractability, we assume a quadratic restoration cost function $C_{R}(e)=k e^{2} / 2$, where $e$ is the effort that unreliable supplier exerts and $k$ is a coefficient related to the rebuild cost. Similar cost functions have been widely used in the operation and marketing literature to model the diminishing impact of effort [28-30]. With the restoration effort $e$, we can formulate the unreliable supplier's profit function if there is a disruption for given values of $q_{u}$ as follows:

$$
\Pi_{s}(e)=-\frac{k e^{2}}{2}+\left(w_{u}-c_{d}\right) \min \left(q_{u}, e\right) .
$$

If the wholesale price $w_{u}$ is less than the postdisruption unit production cost (i.e., $w_{u} \leq c_{d}$ ), the unreliable supplier will not exert effort to restore capacity. Note that our assumption about the restoration cost $C_{R}(e)=k e^{2} / 2$ implies that the marginal effort cost increases with the amount of effort. The unreliable supplier's optimal effort is summarized as follows.

Proposition 1. If $w_{u} \leq c_{d}$, the unreliable supplier will not exert any effort to restore capacity for order fulfillment; otherwise, the supplier's optimal restoration effort level $e^{*}\left(q_{u}\right)$ is increasing in $q_{u}$ and

$$
e^{*}\left(q_{u}\right)=\min \left\{\frac{w_{u}-c_{d}}{k}, q_{u}\right\} .
$$

Obviously, if the unreliable supplier decides to exert effort to rebuild capacity after disruption, the amount of restored capacity will not be more than the order quantity (i.e., $\left.e^{*} \leq q_{u}\right)$. As shown in Figure 2, if $q_{u}$ falls in $0 \leq q_{u} \leq\left(\left(w_{u}-c_{d}\right) / k\right)$, the supplier's restoration effort level $e$ increases with $q_{u}$, which means that the supplier can fully meet the order even if there is a disruption without any additional incentive from the buyer. While $q_{u}$ is falls in $q_{u}>\left(\left(w_{u}-c_{d}\right) / k\right)$, the supplier's restoration effort level $e$ is 


$\begin{array}{cccc}\left(w_{r}, q_{r}\right) & \text { Disruption } & \text { Restoration } & \text { Quantity received } \\ \left(w_{u}, q_{u}\right) & \text { event } & \text { effort } e & \text { by the buyer }\end{array}$

FIGURE 1: Sequence of the events.

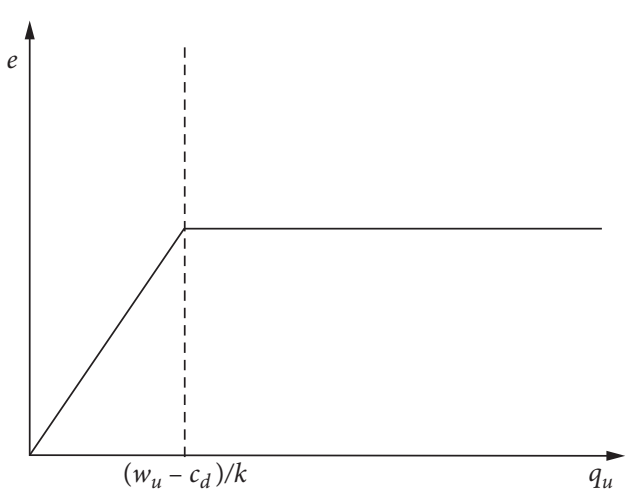

FIGURE 2: The relationship between restoration effort and order quantity.

fixed and is independent with $q_{u}$, and thus the order is not fully satisfied.

4.2. Optimal Procurement Strategy. In all, the buyer can choose among three strategies. The first strategy is ordering from the reliable supplier only (strategy $\mathrm{R}$ ), the second one is ordering from the unreliable supplier only (strategy $\mathrm{U}$ ), and the last one is ordering from both of the suppliers, also referred to as supply diversification strategy (strategy D).

4.2.1. Ordering Only from Reliable Supplier. The buyer orders only from the reliable supplier with fixed wholesale price $w_{r}$. We use $q_{r}$ to denote the order quantity under this strategy. The profit function of the buyer is as follows:

$$
\Pi_{b}^{R}\left(q_{r}\right)=\left(p-w_{r}\right) \min \left(q_{r}, d\right) .
$$

Under the wholesale contract, it is easy to obtain $q_{r}^{*}=d$.

4.2.2. Ordering Only from Unreliable Supplier. The buyer orders only from the unreliable supplier through a wholesale contract $\left(q_{u}, w_{u}\right)$. If the disruption occurs with the possibility of $1-\beta$, the unreliable supplier will lose all the capacity and decide whether to exert restoration effort $e$ to rebuild capacity. We assume that the unreliable supplier will get the restoration capacity $e$ through the restoration effort $e$. From Proposition 1, we know that the restoration capacity depends on the values of $q_{u}$ and $w_{u}$, and the profit function of the buyer is formulated as follows:

$\Pi_{b}^{U}\left(q_{u}, w_{u}\right)=\left(p-w_{u}\right)\left[\beta \min \left(q_{u}, d\right)+(1-\beta) \min \left(e^{*}, d\right)\right]$.

Taking (2) into (4), we have $\Pi_{b}^{U}\left(q_{u}, w_{u}\right)=\left(p-w_{u}\right)$ $\left[\beta \min \left(q_{u}, d\right)+(1-\beta) \min \left(\left(\left(w_{u}-c_{d}\right) / k\right), q_{u}, d\right)\right]$. We consider two cases: when $q_{u}<d$, we have $\Pi_{b}^{U}\left(q_{u}, w_{u}\right)=(p-$ $\left.w_{u}\right)\left[\beta q_{u}+(1-\beta) \min \left(\left(\left(w_{u}-c_{d}\right) / k\right), q_{u}\right)\right]$, which increases with $q_{u}$; when $q_{u} \geq d$, we have $\Pi_{b}^{U}\left(q_{u}, w_{u}\right)=(p-$ $\left.w_{u}\right)\left[\beta d+(1-\beta) \min \left(\left(\left(w_{u}-c_{d}\right) / k\right), d\right)\right]$, which is unrelated to $q_{u}$. We summarize the above results in Lemma 1 .

Lemma 1. If the seller orders from the unreliable supplier only, then $q_{u}^{*}=d$.

From Lemma 1, we rewrite equation (4) as follows:

$$
\Pi_{b}^{U}\left(w_{u}\right)=\left(p-w_{u}\right)\left[\beta d+(1-\beta) \min \left(\frac{w_{u}-c_{d}}{k}, d\right)\right]
$$

where $0 \leq w_{u} \leq p$.

To solve the optimal wholesale price provided to the unreliable supplier, we conduct our analysis based on two cases $c_{d}+k d \leq p$ and $c_{d}+k d>p$ as follows.

When $c_{d}+k d \leq p$, we consider two subcases $\left(\left(w_{u}-\right.\right.$ $\left.\left.c_{d}\right) / k\right) \geq d$ and $\left(\left(w_{u}-c_{d}\right) / k\right)<d$ as follows:

(1) If $\left(\left(w_{u}-c_{d}\right) / k\right) \geq d$, then the profit function is

$$
\Pi_{b}^{U}\left(w_{u}\right)=\left(p-w_{u}\right) d
$$

Since $\Pi_{b}^{U}\left(w_{u}\right)$ decreases with $w_{u}$, we obtain the local maximizer that $\widehat{w}_{u}=k d+c_{d}$ and $\Pi_{b}^{U}\left(\widehat{w}_{u}\right)=\left(p-k d-c_{d}\right) d$.

(2) If $\left(\left(w_{u}-c_{d}\right) / k\right)<d$, we have $c_{d} \leq w_{u}<k d+c_{d}$; then, the profit function is

$$
\begin{aligned}
\Pi_{b}^{U}\left(w_{u}\right)= & -\frac{(1-\beta) w_{u}^{2}}{k}+\left[\frac{(1-\beta)\left(p+c_{d}\right)}{k}-\beta d\right] \\
& \cdot w_{u}-\frac{(1-\beta) p c_{d}}{k}+\beta p d .
\end{aligned}
$$

Since the axis of symmetry of equation (7) is $\left(\left(p+c_{d}\right) / 2\right)-(\beta k d /(2(1-\beta)))$, we have the following scenarios:

(a) When $\left(\left(p+c_{d}\right) / 2\right)-\beta k d /(2(1-\beta)) \leq c_{d}$, we have the local maximizer $\widehat{w}_{u}=c_{d}$ and $\Pi_{b}^{U}\left(\widehat{w}_{u}\right)=$ $\beta d\left(p-c_{d}\right)$.

(b) When $\quad c_{d}<\left(\left(p+c_{d}\right) / 2\right)-(\beta k d /(2(1-\beta)))<c_{d}+$ $k d$, we have $\widehat{w}_{u}=\left(\left(p+c_{d}\right) / 2\right)-(\beta k d /(2(1-\beta)))$ and $\Pi_{b}^{U} \quad\left(\widehat{w}_{u}\right)=\left[\left(\left(p-c_{d}\right) / 2\right)+(\beta k d /(2(1-\beta)))\right]$ $\left[(\beta d / 2)+\left((1-\beta)\left(p-c_{d}\right) / 2 k\right)\right]$.

(c) When $\left(\left(p+c_{d}\right) / 2\right)-(\beta k d /(2(1-\beta))) \geq c_{d}+k d$, we have $\widehat{w}_{u}=c_{d}+k d$ and $\Pi_{b}^{U}\left(\widehat{w}_{u}\right)=d\left[p-k d-c_{d}\right]$.

Thus, we conclude the equilibrium outcomes when $c_{d}+$ $k d \leq p$ as follows:

(1) If $c_{d}+k d \leq p, \quad\left(\left(p+c_{d}\right) / 2\right)-(\beta k d / 2(1-\beta)) \leq c_{d}$, and $k d-(1-\beta)\left(p-c_{d}\right) \leq 0$ or $c_{d}<\left(\left(p+c_{d}\right) / 2\right)-$ $(\beta k d /(2(1-\beta)))<c_{d}+k d$ and $\Pi_{b}^{U}\left(c_{d}+k b\right)>\Pi_{b}^{U}$ 
$\left(\left(p+c_{d}\right) / 2\right)-(\beta k d /(2(1-\beta)))$ or $(3)\left(\left(p+c_{d}\right) / 2\right)-$ $(\beta k d /(2(1-\beta))) \geq c_{d}+k d$, then $\widehat{w}_{u}=c_{d}+k d$ and $\Pi_{b}^{U}=\left(p-c_{d}-k d\right) b$.

(2) If $c_{d}+k d \leq p,\left(\left(p+c_{d}\right) / 2\right)-(\beta k d /(2(1-\beta))) \leq c_{d}$, and $k d-(1-\beta)\left(p-c_{d}\right) \geq 0$, then $\widehat{w}_{u}=c_{d}$ and $\Pi_{b}^{U}=\beta b\left(p-c_{d}\right)$.

(3) If $c_{d}+k b \leq p, c_{d}<\left(\left(p+c_{d}\right) / 2\right)-(\beta k d /(2(1-\beta)))$ $<c_{d}+k b$, and $\Pi_{b}^{U}\left(c_{d}+k b\right) \leq \Pi_{b}^{U}\left(\left(\left(p+c_{d}\right) / 2\right)-\right.$ $(\beta k d /(2(1-\beta))))$, then $\widehat{w}_{u}=\left(\left(p+c_{d}\right) / 2\right)-(\beta k d /$ $(2(1-\beta)))$ and $\Pi_{b}^{U}=\left[\left(\left(p-c_{d}\right) / 2\right)+(\beta k d /(2(1-\right.$ $\beta)))] \quad\left\{\beta b+((1-\beta) / k)\left[\left(\left(p-c_{d}\right) / 2\right)-(\beta k d /(2(1-\right.\right.$ $\beta)))]\}$.

When $c_{d}+k b>p$, we know that $\left(\left(w_{u}-c_{d}\right) / k\right)<$ $b$, i.e., $c_{d}<w_{u}<p$; thus, the profit function is as follows:

$$
\begin{aligned}
\Pi_{b}^{U}= & \max _{w_{u}}\left\{-\frac{(1-\beta) w_{u}^{2}}{k}+\left[\frac{(1-\beta)\left(p+c_{d}\right)}{k}-\beta b\right] w_{u}\right. \\
& \left.-\frac{(1-\beta) p c_{d}}{k}+\beta p b\right\} .
\end{aligned}
$$

Since the axis of symmetry of Function (8) is $\left(\left(p+c_{d}\right) / 2\right)-(\beta k d /(2(1-\beta)))$, we have the following scenarios:

(a) If $\left(\left(p+c_{d}\right) / 2\right)-(\beta k d /(2(1-\beta))) \leq c_{d}$, we have the local maximizer $\widehat{w}_{u}=c_{d}$ and $\Pi_{b}^{U}=\beta b\left(p-c_{d}\right)$.

(b) If $c_{d}<\left(\left(p+c_{d}\right) / 2\right)-(\beta k d /(2(1-\beta)))<p$, we have $\widehat{w}_{u}=\left(\left(p+c_{d}\right) / 2\right)-(\beta k d /(2(1-\beta)))$ and $\Pi_{b}^{U}=$ $\left[\left(\left(p-c_{d}\right) / 2\right)+(\beta k d /(2(1-\beta)))\right]\{\beta b+((1-\beta) / k)$ $\left.\left[\left(\left(p-c_{d}\right) / 2\right)-(\beta k d /(2(1-\beta)))\right]\right\}$.

(c) If $\left(\left(p+c_{d}\right) / 2\right)-(\beta k d /(2(1-\beta))) \geq p$, we have $\widehat{w}_{u}=$ $p$ and $\Pi_{b}^{U}=0$.

According to the above analysis, we summarize our equilibrium results in Proposition 2.

Proposition 2. If the buyer only procures from the unreliable supplier, the equilibrium decision and profit of the buyer are summarized as follows:

(i) If $c_{d}+k b \leq p$, (1) $\left(\left(p+c_{d}\right) / 2\right)-(\beta k d /(2(1-\beta))) \leq$ $c_{d}$, and $k b-(1-\beta)\left(p-c_{d}\right) \leq 0$ or (2) $c_{d}<((p+$ $\left.\left.c_{d}\right) / 2\right)-(\beta k d /(2(1-\beta)))<c_{d}+k b$ and $\Pi_{b}^{U}\left(c_{d}+\right.$ $k b)>\Pi_{b}^{U}\left(\left(\left(p+c_{d}\right) / 2\right)-(\beta k d /(2(1-\beta)))\right)$ or (3) $\left(\left(p+c_{d}\right) / 2\right)-(\beta k d /(2(1-\beta))) \geq c_{d}+k b, \quad$ then $w_{u}^{*}=c_{d}+k b$ and $\Pi_{b}^{U}=\left(p-c_{d}-k b\right) b$.

(ii) If (1) $c_{d}+k b \leq p, c_{d}<\left(\left(p+c_{d}\right) / 2\right)-(\beta k d /(2(1-$ $\beta)))<c_{d}+k b$, and $\Pi_{b}^{U}\left(c_{d}+k b\right) \leq \Pi_{b}^{U}\left(\left(\left(p+c_{d}\right) / 2\right)-\right.$ $(\beta k d /(2(1-\beta))))$ or $(2) c_{d}+k b>p$ and $c_{d}<((p+$ $\left.\left.c_{d}\right) / 2\right)-(\beta k d /(2(1-\beta)))<p$, then $w_{u}^{*}=((p+$ $\left.\left.c_{d}\right) / 2\right)-(\beta k d /(2(1-\beta)))$ and $\Pi_{b}^{U}=\left[\left(\left(p-c_{d}\right) / 2\right)+\right.$ $(\beta k d /(2(1-\beta)))] \quad\left\{\beta b+((1-\beta) / k)\left[\left(\left(p-c_{d}\right) / 2\right)-\right.\right.$ $(\beta k d /(2(1-\beta)))]\}$.

(iii) If (1) $c_{d}+k b \leq p,\left(\left(p+c_{d}\right) / 2\right)-(\beta k d /(2(1-\beta))) \leq$ $c_{d}$, and $k b-(1-\beta)\left(p-c_{d}\right) \geq 0$ or (2) $c_{d}+k b>p$ and $\left(\left(p+c_{d}\right) / 2\right)-(\beta k d /(2(1-\beta))) \leq c_{d}$, then $w_{u}^{*}$ $=c_{d}$ and $\Pi_{b}^{U}=\beta b\left(p-c_{d}\right)$.

(iv) If $c_{d}+k b>p$ and $\left(\left(p+c_{d}\right) / 2\right)-(\beta k d /(2(1-$ $\beta))) \geq p$, then $w_{u}^{*}=p$ and $\Pi_{b}^{U}=0$.

4.2.3. Supply Diversification Strategy. In this part, we discuss the optimal strategy of the buyer when ordering from both suppliers. We assume that $q_{u}+q_{r}=b$ and the buyer's profit is

$$
\begin{aligned}
\Pi_{b}^{D}\left(w_{u}, q_{u}\right)= & \beta\left(p b-w_{u} q_{u}-w_{r} q_{r}\right) \\
& +(1-\beta)\left[p\left(e^{*}+q_{r}\right)-w_{u} e^{*}-w_{r} q_{r}\right],
\end{aligned}
$$

where $e^{*}=\min \left\{\left(w_{u}-c_{d}\right) / k, q_{u}\right\}$ and $q_{r}=b-q_{u}$. We further consider two cases $q_{u} \leq\left(w_{u}-c_{d}\right) / k$ and $q_{u}>\left(w_{u}-c_{d}\right) / k$ as follows.

When $q_{u} \leq\left(w_{u}-c_{d}\right) / k$, we have

$$
\begin{aligned}
\Pi_{b}^{D}\left(w_{u}, q_{u}\right) & =p b-q_{u} w_{u}-\left(b-q_{u}\right) w_{r} \\
& =\left(p-w_{r}\right) b+\left(w_{r}-w_{u}\right) q_{u} .
\end{aligned}
$$

Since $\Pi_{b}^{D}\left(w_{u}, q_{u}\right)$ is decreasing in $w_{u}$, we have $w_{u}=k q_{u}+c_{d}$. Taking it back into equation (10), we have

$$
\Pi_{b}^{D}\left(q_{u}\right)=-k q_{u}^{2}+\left(w_{r}-c_{d}\right) q_{u}+\left(p-w_{r}\right) b .
$$

Since the axis of symmetry of the function is $q_{u}=\left(\left(w_{r}-c_{d}\right) / 2 k\right)$, for $0 \leq q_{u} \leq b$, we have the following two subcases $0 \leq\left(\left(w_{r}-c_{d}\right) / 2 k\right) \leq b$ and $\left(\left(w_{r}-c_{d}\right) / 2 k\right)>b$ :

(1) If $0 \leq\left(\left(w_{r}-c_{d}\right) / 2 k\right) \leq b$, then $\hat{q_{u}}=\left(\left(w_{r}-c_{d}\right) / 2 k\right)$, $\widehat{w}_{u}=\left(\left(w_{r}+c_{d}\right) / 2\right)$, and $\Pi_{b}^{D}\left(\widehat{q}_{u}, \widehat{w}_{u}\right)=\left(\left(w_{r}-c_{d}\right)^{2} /\right.$ $4 k)+\left(p-w_{r}\right) b$.

(2) If $\left(\left(w_{r}-c_{d}\right) / 2 k\right)>b$, then $\widehat{q}_{u}=b, \widehat{w}_{u}=k b+c_{d}$ and $\Pi_{b}^{D}\left(\widehat{q}_{u}, \widehat{w}_{u}\right)=\left(p-c_{d}\right) b-k b^{2}$.

When $q_{u}>\left(\left(w_{r}-c_{d}\right) / 2 k\right)$, we have

$$
\begin{aligned}
\Pi_{b}^{D}\left(w_{u}, q_{u}\right)= & {\left[w_{r}-\beta w_{u}-(1-\beta) p\right] q_{u} } \\
& +\left(p-w_{r}\right) b+\frac{1-\beta}{k}\left[-w^{2}+\left(p+c_{d}\right) w-p c_{d}\right]
\end{aligned}
$$

We can easily obtain that $c_{d} \leq w_{u} \leq k b+c_{d}$; then we consider three subcases $\left(\left(w_{r}-(1-\beta) p\right) / \beta\right)<c_{d}, \quad c_{d} \leq$ $\left(\left(w_{r}-(1-\beta) p\right) / \beta\right)<k b+c_{d}$, and $\quad\left(\left(w_{r}-(1-\beta) p\right) / \beta\right) \geq$ $k b+c_{d}$ as follows:

(1) If $\left(\left(w_{r}-(1-\beta) p\right) / \beta\right)<c_{d}$, we have the coefficient of $q_{u}$ in (13) which is $w_{r}-\beta w_{u}-(1-\beta) p<0$, so $\Pi_{b}^{D}\left(w_{u}, q_{u}\right)$ is decreasing in $q_{u}$; then $\widehat{q_{u}}=$ $\left(\left(w_{u}-c_{d}\right) / k\right)$. Then, we can rewrite equation (12) as follows:

$\Pi_{b}^{D}\left(w_{u}\right)=-\frac{w_{u}^{2}}{k}+\frac{\left(w_{r}+c_{d}\right) w_{u}}{k}-\frac{w_{r} c_{d}}{k}+\left(p-w_{r}\right) b$.

Since the axis of symmetry of equation (13) is $w_{u}=\left(\left(w_{r}+c_{d}\right) / 2\right)$, for $c_{d} \leq w_{u} \leq k b+c_{d}$, then we have the following two scenarios: 
(a) If $\left(\left(w_{r}+c_{d}\right) / 2\right) \leq k b+c_{d}$, we have $\widehat{w}_{u}=\left(\left(w_{r}+\right.\right.$ $\left.\left.c_{d}\right) / 2\right), \quad \widehat{q_{u}}=\left(\left(w_{r}-c_{d}\right) / 2 k\right)$, and $\Pi_{b}^{D}\left(\widehat{w}_{u}, \widehat{q_{u}}\right)=$ $\left(\left(w_{r}-c_{d}\right)^{2} / 4 k\right)+\left(p-w_{r}\right) b$.

(b) If $\left(\left(w_{r}+c_{d}\right) / 2\right)>k b+c_{d}$, we have $\widehat{w}_{u}=k b+c_{d}$, $\widehat{q_{u}}=b$ and $\Pi_{b}^{D}\left(\widehat{w}_{u}, \widehat{q_{u}}\right)=\left(p-c_{d}\right) b-k b^{2}$.

(2) If $c_{d} \leq\left(\left(w_{r}-(1-\beta) p\right) / \beta\right)<k b+c_{d}$, we have the following two scenarios:

(a) If $c_{d} \leq w_{u} \leq\left(w_{r}-(1-\beta) p / \beta\right)$, then $w_{r}-\beta w_{u}-$ $(1-\beta) p \geq 0$, so $\Pi_{b}^{D}\left(w_{u}, q_{u}\right)$ is increasing in $q_{u}$, for $0 \leq q_{u} \leq b$; we obtain $\widehat{q_{u}}=b$. Taking it into equation (12), we have

$$
\Pi_{b}^{D}\left(w_{u}\right)=-\frac{1-\beta}{k}\left[w_{u}^{2}-\left(p+c_{d}-\frac{\beta k b}{1-\beta}\right) w_{u}+p c_{d}\right]+\beta p b .
$$

Since the axis of symmetry of equation (14) is $w_{u}=\left(\left(p+c_{d}\right) / 2\right)-(\beta k d /(2(1-\beta)))$, we thus conduct the following discussion:

If $\left(\left(p+c_{d}\right) / 2\right)-(\beta k d /(2(1-\beta)))<c_{d}$, then $\widehat{w}_{u}=$ $c_{d}, \widehat{q_{u}}=b$, and $\Pi_{b}^{D}\left(\widehat{w}_{u}, \widehat{q_{u}}\right)=\beta\left(p-c_{d}\right) b$.

If $c_{d} \leq\left(\left(p+c_{d}\right) / 2\right)-(\beta k d /(2(1-\beta)))<\left(\left(w_{r}-(1-\right.\right.$ $\beta) p) / \beta)$, then $\widehat{w}_{u}=\left(\left(p+c_{d}\right) / 2\right)-(\beta k d /(2(1-\beta)))$, $\widehat{q_{u}}=b$, and $\Pi_{b}^{D}\left(\widehat{w}_{u}, \widehat{q_{u}}\right)=((1-\beta) / k)\left[\widehat{w}_{u}=((p+\right.$ $\left.\left.\left.c_{d}\right) / 2\right)-(\beta k d /(2(1-\beta)))\right]^{2}-\left(\left((1-\beta) p c_{d}\right) / k\right)+\beta p b$. If $\quad\left(\left(p+c_{d}\right) / 2\right)-(\beta k d /(2(1-\beta))) \geq\left(\left(w_{r}-(1-\right.\right.$ $\beta) p) / \beta)$, then $\widehat{w}_{u}=\left(\left(w_{r}-(1-\beta) p\right) / \beta\right), \widehat{q}_{u}=b$, and $\Pi_{b}^{D}\left(\widehat{w}_{u}, \widehat{q_{u}}\right)=p\left(w_{r}+c_{d}\right)-(1-\beta)\left(p^{2}+w_{r} c_{d}\right)$.

(b) If $\left(\left(w_{r}-(1-\beta) p\right) / \beta\right)<w_{u} \leq k b+c_{d}$, then $w_{r}-$ $\beta w_{u}-(1-\beta) p<0$, so $\Pi_{b}^{D}\left(w_{u}, q_{u}\right)$ is decreasing in $q_{u}$, for $\left(\left(w_{u}-c_{d}\right) / k\right) \leq q_{u} \leq b$; we obtain $\widehat{q}_{u}=$ $\left(\left(w_{u}-c_{d}\right) / k\right)$. Taking it into (13), we have

Since the axis of symmetry of (16) is $w_{u}=\left(\left(w_{r}+\right.\right.$ $\left.c_{d}\right) / 2 k$ ), we thus conduct the following discussion:

If $\left(\left(w_{r}+c_{d}\right) / 2 k\right)<\left(\left(w_{r}-(1-\beta) p\right) / \beta\right)$, then $\widehat{w}_{u}=$ $\left(\left(w_{r}-(1-\beta) p\right) / \beta\right), \quad \widehat{q_{u}}=\left(\left(p-c_{d}\right) / k\right)-\left(\left(p-w_{r}\right) /\right.$ $\beta k)$, and $\Pi_{b}^{D}\left(\widehat{w}_{u}, \widehat{q_{u}}\right)=-\left((1-\beta)\left(p-w_{r}\right)^{2} / k \beta^{2}\right)+$ $\left(\left((1-\beta)\left(p^{2}+w_{r} c_{d}-p w_{r}-p c_{d}\right)\right) / k \beta\right)+\left(p-w_{r}\right) b$.

If $\quad\left(\left(w_{r}-(1-\beta) p\right) / \beta\right) \leq\left(\left(w_{r}+c_{d}\right) / 2 k\right)<k b+c_{d}$, then $\widehat{w}_{u}=\left(\left(w_{r}+c_{d}\right) / 2 k\right), \widehat{q_{u}}=\left(\left(w_{r}-c_{d}\right) / 2 k\right)$, and $\Pi_{b}^{D}\left(\widehat{w}_{u}, \widehat{q}_{u}\right)=\left(\left(w_{r}-c_{d}\right)^{2} / 4 k\right)+\left(p-w_{r}\right) b$.

If $\left(\left(w_{r}+c_{d}\right) / 2 k\right) \geq k b+c_{d}$, then $\widehat{w}_{u}=k b+c_{d}$, $\widehat{q_{u}}=b$, and $\Pi_{b}^{D}\left(\widehat{w}_{u}, \widehat{q_{u}}\right)=\left(p-c_{d}\right) b-k b^{2}$.

(3) If $\left(\left(w_{r}-(1-\beta) p\right) / \beta\right) \geq k b+c_{d}$, we have $w_{r}-$ $\beta w_{u}-(1-\beta) p>0$, so $\widehat{q}_{u}=b$. Taking it into equation (12), we have

$$
\begin{aligned}
\Pi_{b}^{D}\left(w_{u}\right)= & -\frac{1}{k}\left[w_{u}^{2}-\left(w_{r}+c_{d}\right) w_{u}+w_{r} c_{d}\right] \\
& +\left(p-w_{r}\right) b .
\end{aligned}
$$

Since the axis of symmetry of equation (16) is $\widehat{w}_{u}=\left(\left(p+c_{d}\right) / 2\right)-(\beta k d /(2(1-\beta)))$, for $c_{d} \leq w_{u} \leq k b+c_{d}$, we thus conduct the following discussion:

$$
\Pi_{b}^{D}\left(w_{u}\right)=-\frac{1-\beta}{k}\left[w_{u}^{2}-\left(p+c_{d}-\frac{\beta k b}{1-\beta}\right) w_{u}+p c_{d}\right]+\beta p b
$$

If $\left(\left(p+c_{d}\right) / 2\right)-(\beta k d /(2(1-\beta)))<c_{d}$, then $\widehat{w}_{u}=c_{d}$, $\widehat{q_{u}}=b$, and $\Pi_{b}^{D}\left(\widehat{w}_{u}, \widehat{q}_{u}\right)=\beta\left(p-c_{d}\right) b$.

If $c_{d} \leq\left(\left(p+c_{d}\right) / 2\right)-(\beta k d /(2(1-\beta)))<k b+c_{d}$, then $\widehat{w}_{u}=\left(\left(p+c_{d}\right) / 2\right)-(\beta k d /(2(1-\beta))), \quad \widehat{q}_{u}=b, \quad$ and $\Pi_{b}^{D}\left(\widehat{w}_{u}, \widehat{q_{u}}\right)=((1-\beta) / k) \quad\left[\left(\left(p+c_{d}\right) / 2\right)-(\beta k d /(2(1-\right.$ $\beta)))]^{2}-\left((1-\beta) p c_{d} / k\right)+\beta p b$.

If $\left(\left(p+c_{d}\right) / 2\right)-(\beta k d /(2(1-\beta))) \geq k b+c_{d}$, then $\widehat{w}_{u}=$ $k b+c_{d}, \widehat{q_{u}}=b$, and $\Pi_{b}^{D}\left(\widehat{w}_{u}, \widehat{q_{u}}\right)=\left(p-c_{d}\right) b-k b^{2}$.

According to the above analysis, we have the following discussions to obtain our equilibrium results when the buyer adopts supply diversification strategy.

Case 1. If $\left(\left(w_{r}-(1-\beta) p\right) / \beta\right)<c_{d}$ and $\left(\left(w_{r}+c_{d}\right) / 2 k\right) \leq$ $k d+c_{d}$, the analysis is shown in Figure 3 .

As we can see, for $0 \leq q_{u} \leq b$ and $c_{d} \leq w_{u} \leq k b+c_{d}$, the feasible region is a rectangle with an oblique line cut into two parts, where the solution becomes better along the direction of the arrow. So under this circumstance, we obtain the global optimal solutions $w_{u}^{*}=\left(\left(w_{r}+c_{d}\right) / 2\right)$ and $q_{u}^{*}=$ $\left(\left(w_{r}-c_{d}\right) / 2 k\right)$, and the optimal profit is $\Pi_{b}^{D}\left(w_{u}^{*}\right.$, $\left.q_{u}^{*}\right)=\left(\left(w_{r}-c_{d}\right)^{2} / 4 k\right)+\left(p-w_{r}\right) b$.

Case 2. If $\left(\left(w_{r}-(1-\beta) p\right) / \beta\right)<c_{d} \leq k d+c_{d}<\left(\left(w_{r}+c_{d}\right) / 2\right)$, we have our analysis as shown in Figure 4.

It is easy to obtain the global optimal solution which is $w_{u}^{*}=k b+c_{d}$ and $q_{u}^{*}=b$, which is the intersection of the lines $q_{u}=b$ and $q_{u}=\left(w_{u}-c_{d}\right) / k$, and the optimal profit is $\Pi_{b}^{D}\left(w_{u}^{*}, q_{u}^{*}\right)=\left(p-c_{d}\right) b-k b^{2}$.

Case 3. If $\left(\left(p+c_{d}\right) / 2\right)-(\beta k d /(2(1-\beta)))<c_{d}<\left(\left(w_{r}+c_{d}\right) /\right.$ $2)<\left(\left(w_{r}-(1-\beta) p\right) / \beta\right)<k b+c_{d}$, the analysis is shown in Figure 5 .

We can see that the feasible region is cut into three parts with a local optimal solution in each part. We can easily find the global optimums $w_{u}^{*}=c_{d}$ and $q_{u}^{*}=b$, and the optimal profit is $\Pi_{b}^{D}\left(w_{u}^{*}, q_{u}^{*}\right)=\beta\left(p-c_{d}\right) b$.

Case 4. If $\left(\left(p+c_{d}\right) / 2\right)-(\beta k d /(2(1-\beta)))<c_{d} \leq\left(\left(w_{r}-(1-\right.\right.$ $\beta) p) / \beta)<\left(\left(w_{r}+c_{d}\right) / 2\right)<k b+c_{d}$, the analysis is shown in Figure 6 .

As we can see, the feasible region is divided into three parts which is the same as in Figure 5, but the difference is that there are two similar local optimums and we cannot intuitively obtain the global optimum. Thus, we need to compare the profit of the two points $\left(c_{d}, b\right)$ and $\left(\left(\left(w_{r}+c_{d}\right) / 2\right),\left(\left(w_{r}-c_{d}\right) / 2 k\right)\right)$, and the optimal profit is $\max \left\{\Pi_{b}^{D}\left(c_{d}, b\right), \Pi_{b}^{D}\left(\left(\left(w_{r}+c_{d}\right) / 2\right),\left(\left(w_{r}-c_{d}\right) / 2 k\right)\right)\right\}$.

Case 5. If $\left(\left(p+c_{d}\right) / 2\right)-(\beta k d /(2(1-\beta)))<c_{d} \leq\left(\left(w_{r}-\right.\right.$ $(1-\beta) p) / \beta)<k b+c_{d}<\left(\left(w_{r}+c_{d}\right) / 2\right)$, the analysis is shown in Figure 7.

As we can see, there are two local optimums. Since $\left(\left(p+c_{d}\right) / 2\right)-(\beta k d /(2(1-\beta)))<c_{d}$, we compare the profits 


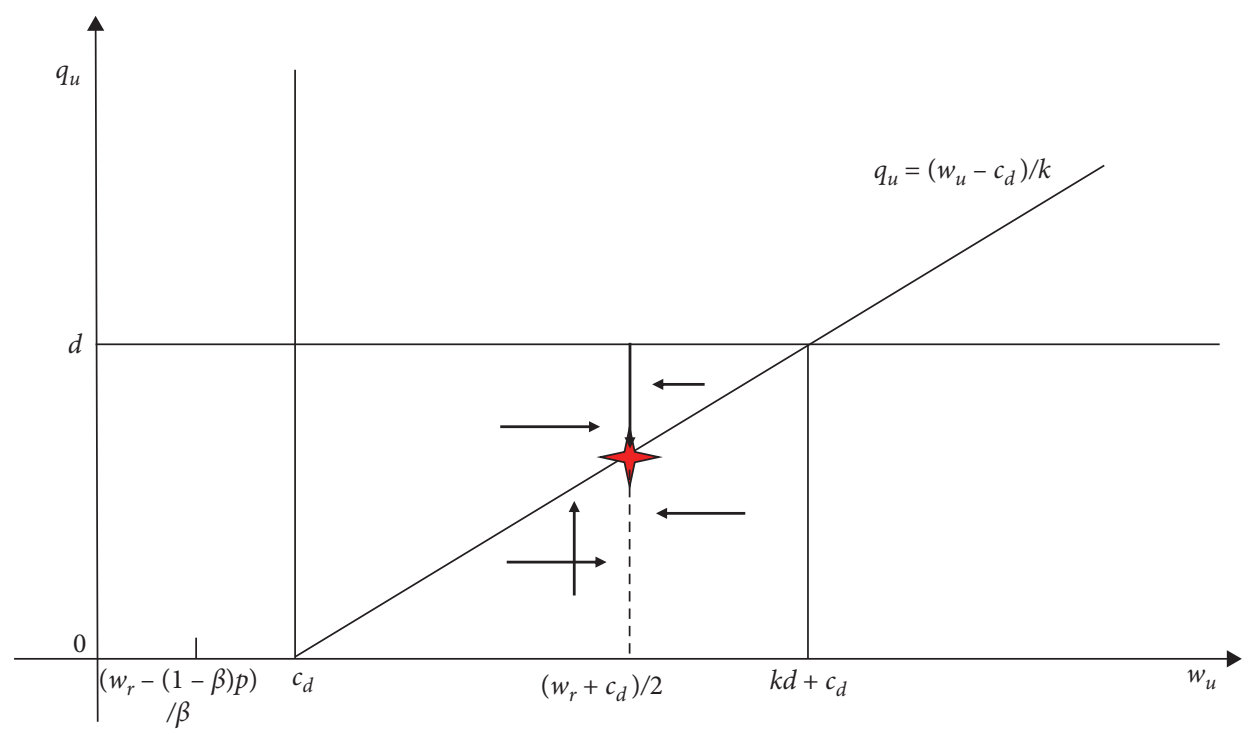

Figure 3: Case 1: $\left(\left(w_{r}-(1-\beta) p\right) / \beta\right)<c_{d}$ and $\left(\left(w_{r}+c_{d}\right) / 2\right) \leq k d+c_{d}$.

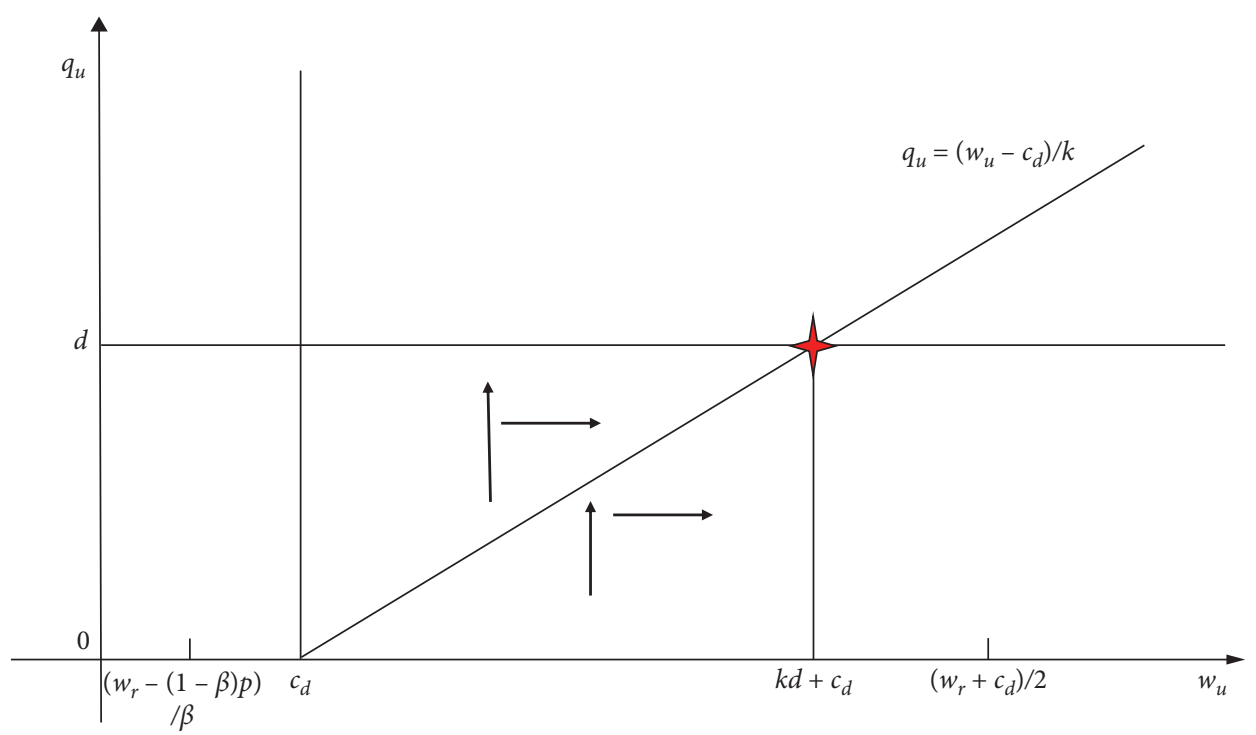

Figure 4: Case 2: $\left(\left(w_{r}-(1-\beta) p\right) / \beta\right)<c_{d} \leq k d+c_{d}<\left(\left(w_{r}+c_{d}\right) / 2\right)$.

of the two points $\left(c_{d}, b\right)$ and $(k b, b)$ and find that $\Pi_{b}^{D}\left(c_{d}\right.$, $b) \geq \Pi_{b}^{D}(k b, b)$, so the global optimum is $w_{u}^{*}=c_{d}$ and $q_{u}^{*}=b$, and the optimal profit is $\Pi_{b}^{D}\left(w_{u}^{*}, q_{u}^{*}\right)=\beta\left(p-c_{d}\right) b$.

Case 6. If $c_{d} \leq\left(\left(p+c_{d}\right) / 2\right)-\beta k b / 2(1-\beta)<\left(\left(w_{r}-(1-\right.\right.$ $\beta) p) / \beta)$ and $\left(\left(w_{r}+c_{d}\right) / 2\right) \leq\left(\left(w_{r}-(1-\beta) p\right) / \beta\right)<k b+c_{d}$, the analysis is shown in Figure 8 .

Similarly, there are three local optimums, but we can easily obtain that the global optimal solution is $w_{u}^{*}=((p+$ $\left.\left.c_{d}\right) / 2\right)-(\beta k d /(2(1-\beta)))$ and $q_{u}^{*}=b$.

Case 7. If $c_{d} \leq\left(\left(p+c_{d}\right) / 2\right)-(\beta k b / 2(1-\beta))<\left(\left(w_{r}-(1-\beta)\right.\right.$ $p) / \beta)<\left(\left(w_{r}+c_{d}\right) / 2\right) \leq k b+c_{d}$, the analysis is shown in Figure 9 .

We can obtain that the local optimums are $\left(\left(\left(p+c_{d}\right) / 2\right)-(\beta k b /(2(1-\beta))), b\right)$ and $\left(w_{r}+c_{d} / 2,\left(w_{r}-\right.\right.$ $\left.\left.c_{d}\right) / 2 k\right)$. The optimal profit is $\max \left\{\Pi_{b}^{D}\left(\left(\left(p+c_{d}\right) / 2\right)-\right.\right.$ $\left.(\beta k d /(2(1-\beta))), b), \Pi_{b}^{D}\left(\left(w_{r}+c_{d}\right) / 2,\left(w_{r}-c_{d}\right) / 2 k\right)\right\}$.

Case 8. If $c_{d} \leq\left(\left(p+c_{d}\right) / 2\right)-(\beta k d /(2(1-\beta)))<\left(\left(w_{r}-\right.\right.$ $(1-\beta) p) / \beta)<k b+c_{d} \leq\left(\left(w_{r}+c_{d}\right) / 2\right)$, the analysis is shown in Figure 10.

We can obtain the two local optimums $\left(\left(\left(p+c_{d}\right) / 2\right)-\right.$ $(\beta k d /(2(1-\beta))), b)$ and $\left(k b+c_{d}, b\right)$. The optimal profit is $\max \left\{\Pi_{b}^{D}\left(\left(\left(p+c_{d}\right) / 2\right)-(\beta k d /(2(1-\beta))), b\right), \Pi_{b}^{D}(k b+\right.$ $\left.\left.c_{d}, b\right)\right\}$.

Case 9. If $c_{d}<\left(\left(w_{r}+c_{d}\right) / 2\right)<\left(\left(w_{r}-(1-\beta) p\right) / \beta\right) \leq((p+$ $\left.\left.c_{d}\right) / 2\right)-(\beta k d /(2(1-\beta)))$ and $\left(w_{r}-(1-\beta) p / \beta\right)<k b+c_{d}$, the analysis is shown in Figure 11.

We can see that $\left(\left(\left(w_{r}+c_{d}\right) / 2\right),\left(\left(w_{r}-c_{d}\right) / 2 k\right)\right)$ is the worst solution, so the best solution is either $\left(\left(\left(w_{r}-(1-\right.\right.\right.$ 


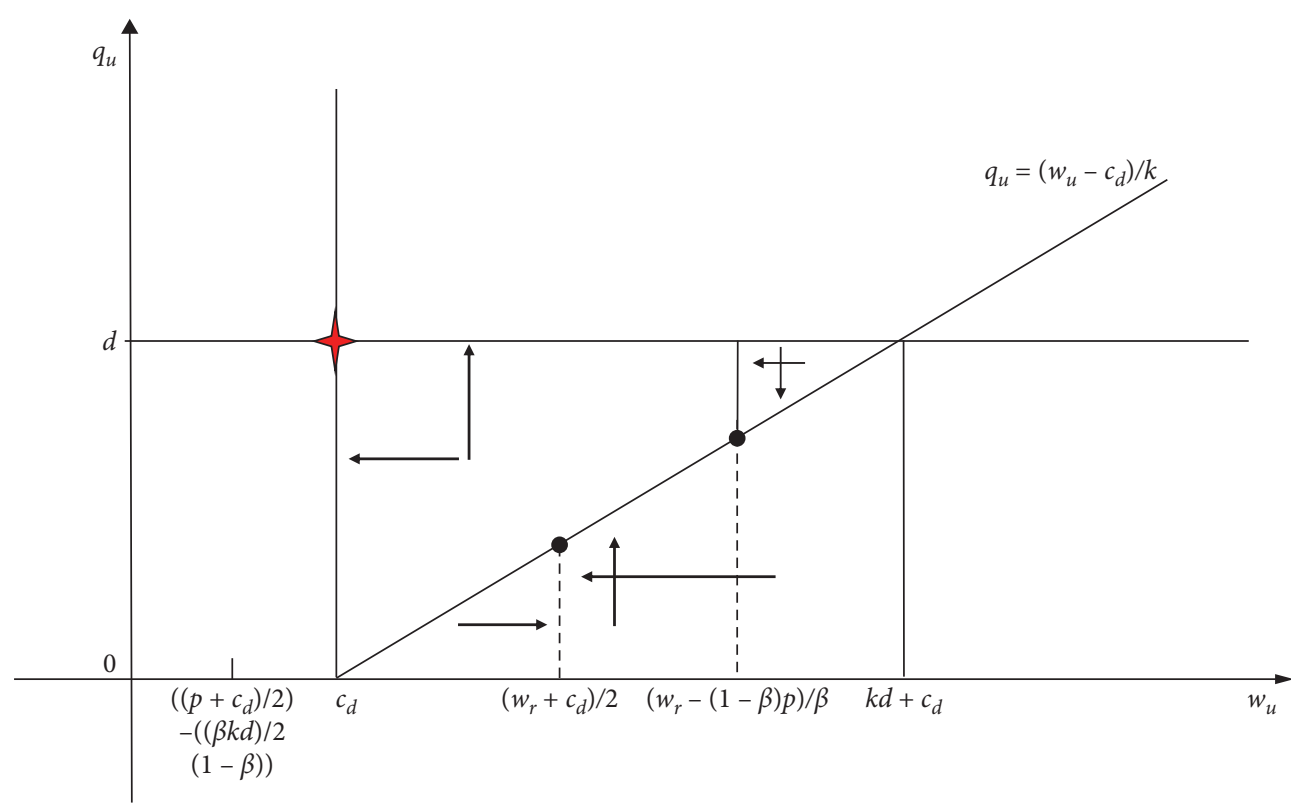

Figure 5: Case 3: $\left(\left(p+c_{d}\right) / 2\right)-(\beta k d /(2(1-\beta)))<c_{d}<\left(\left(w_{r}+c_{d}\right) / 2\right)<\left(\left(w_{r}-(1-\beta) p\right) / \beta\right)<k b+c_{d}$.

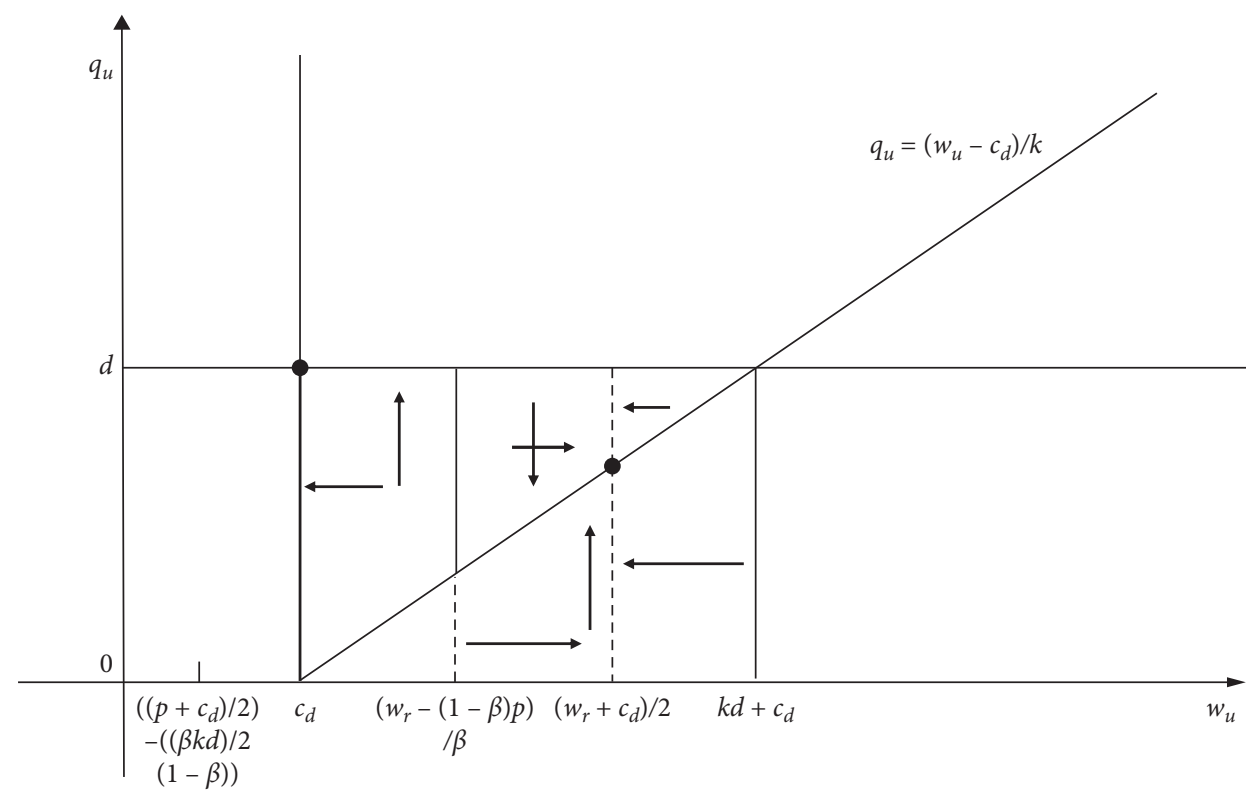

Figure 6: Case 4: $\left(\left(p+c_{d}\right) / 2\right)-(\beta k d /(2(1-\beta)))<c_{d} \leq\left(\left(w_{r}-(1-\beta) p\right) / \beta\right)<\left(\left(w_{r}+c_{d}\right) / 2\right)<k b+c_{d}$.

$\beta) p) / \beta), b)$ or $\quad\left(\left(\left(w_{r}-(1-\beta) p\right) / \beta\right),\left(\left(p+c_{d}\right) / 2\right)-(\beta k b / 2\right.$ $(1-\beta)))$. The profit of the points is $\Pi_{b}^{D}\left(\left(\left(w_{r}-\right.\right.\right.$ $(1-\beta) p) / \beta), b)=p\left(w_{r}+c_{d}\right)-(1-\beta)\left(p^{2}+w_{r} c_{d}\right) \quad$ and $\Pi_{b}^{D}\left(\left(\left(w_{r}-(1-\beta) p\right) / \beta\right),\left(\left(p+c_{d}\right) / 2\right)-(\beta k d /(2(1-\beta)))\right)=$ $-\left((1-\beta)\left(p-w_{r}\right)^{2} / k \beta^{2}\right)+\left((1-\beta)\left(p^{2}+w_{r} c_{d}-p w_{r}-p c_{d}\right) /\right.$ $k \beta)+\left(p-w_{r}\right) b$, and the optimal profit is the bigger one.

Case 10. If $c_{d} \leq\left(\left(w_{r}-(1-\beta) p\right) / \beta\right) \leq\left(\left(w_{r}+c_{d}\right) / 2\right)<k b+$ $c_{d}$ and $\left(\left(p+c_{d}\right) / 2\right)-(\beta k d /(2(1-\beta))) \geq\left(\left(w_{r}-(1-\beta) p\right) /\right.$ $\beta)$, the analysis is shown in Figure 12 .
We can easily obtain the optimal solutions $w_{u}^{*}=\left(\left(w_{r}+\right.\right.$ $\left.c_{d}\right) / 2$ ) and $q_{u}^{*}=\left(\left(w_{r}-c_{d}\right) / 2 k\right)$, and the optimal profit is $\Pi_{b}^{D}\left(w_{u}^{*}, q_{u}^{*}\right)=\left(\left(w_{r}-c_{d}\right)^{2} / 4 k\right)+\left(p-w_{r}\right) b$.

Case 11. If $c_{d} \leq\left(\left(w_{r}-(1-\beta) p\right) / \beta\right) \leq\left(\left(p+c_{d}\right) / 2\right)-(\beta k d /$ $(2(1-\beta)))$ and $\left(\left(w_{r}+c_{d}\right) / 2\right) \geq k b+c_{d}$, the analysis is shown in Figure 13.

It is easy to find that the optimal solution is $w_{u}^{*}=b+c_{d}$ and $q_{u}^{*}=b$, and the optimal profit is $\Pi_{b}^{D}\left(w_{u}^{*}\right.$, $\left.q_{u}^{*}\right)=\left(p-c_{d}\right) b-k b^{2}$. 


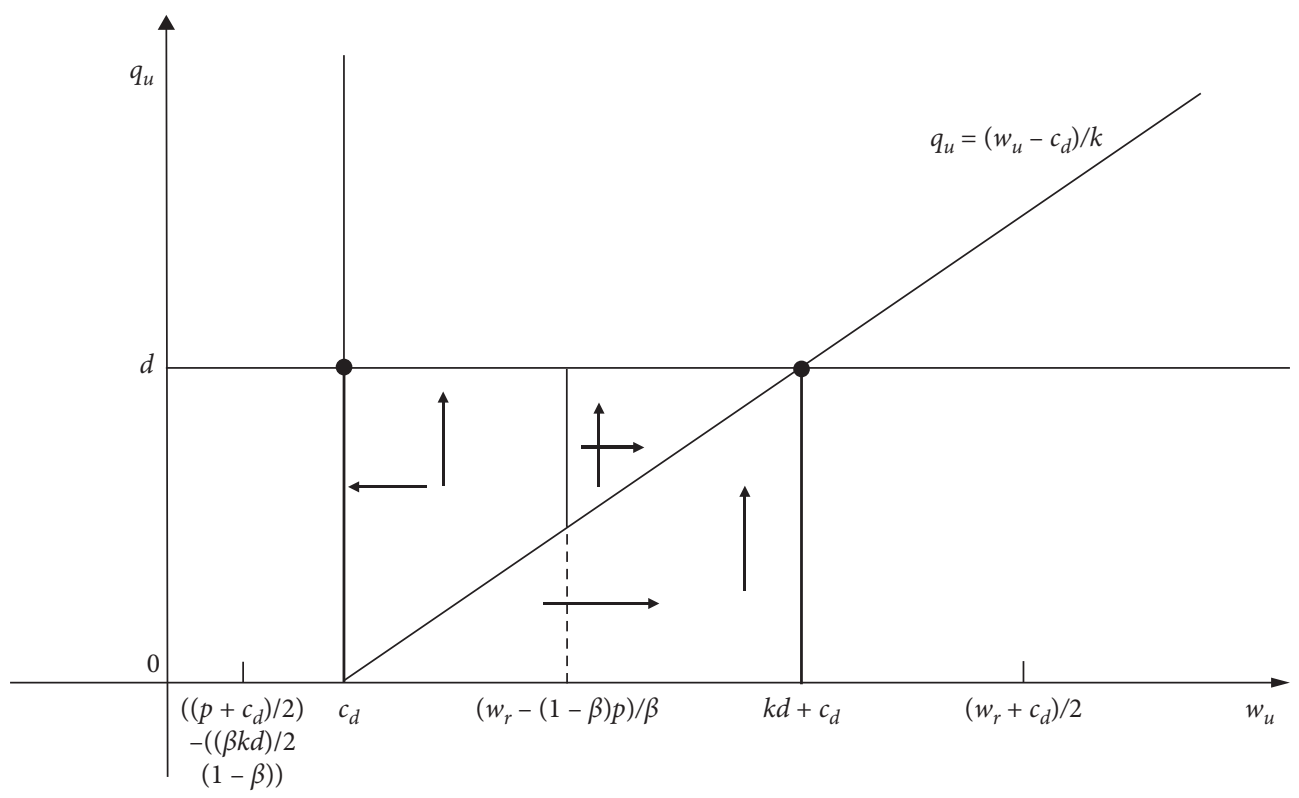

Figure 7: Case 5: $\left(\left(p+c_{d}\right) / 2\right)-(\beta k d /(2(1-\beta)))<c_{d} \leq\left(\left(w_{r}-(1-\beta) p\right) / \beta\right)<k b+c_{d}<\left(\left(w_{r}+c_{d}\right) / 2\right)$.

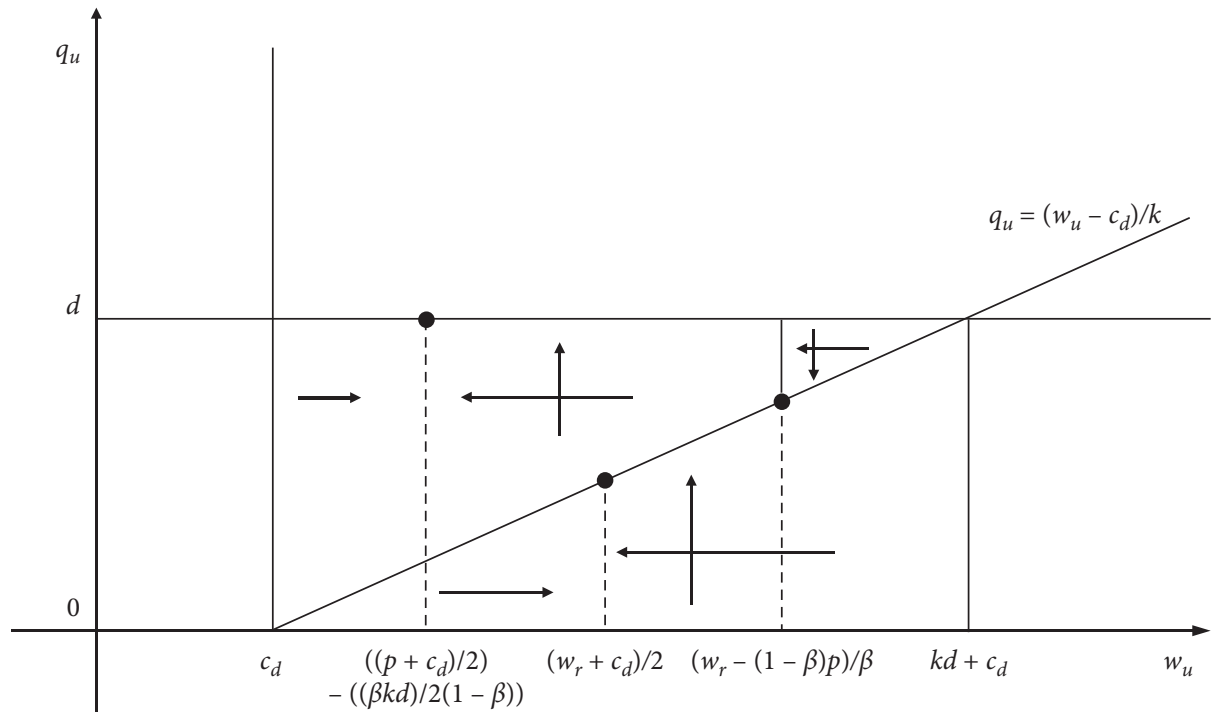

Figure 8: Case 6: $c_{d} \leq\left(\left(p+c_{d}\right) / 2\right)-(\beta k b / 2(1-\beta))<\left(\left(w_{r}-(1-\beta) p\right) / \beta\right)$ and $\left(\left(w_{r}+c_{d}\right) / 2\right) \leq\left(\left(w_{r}-(1-\beta) p\right) / \beta\right)<k b+c_{d}$.

Case 12. If $\left(\left(p+c_{d}\right) / 2\right)-(\beta k d /(2(1-\beta)))<c_{d}<\left(\left(w_{r}+\right.\right.$ $\left.\left.c_{d}\right) / 2\right)<k b+c_{d}<\left(\left(w_{r}-(1-\beta) p\right) / \beta\right)$, the analysis is shown in Figure 14.

As we can see, the global optimum is $w_{u}^{*}=c_{d}$ and $q_{u}^{*}=b$, and the optimal profit is $\Pi_{b}^{D}\left(w_{u}^{*}, q_{u}^{*}\right)=\beta\left(p-c_{d}\right) b$.

Case 13. If $\left(\left(p+c_{d}\right) / 2\right)-(\beta k d /(2(1-\beta)))<c_{d}<k b+$ $c_{d}<\left(\left(w_{r}+c_{d}\right) / 2\right)$ and $\left(\left(w_{r}-(1-\beta) p\right) / \beta\right) \geq k b+c_{d}$, the analysis is shown in Figure 15.

At this circumstance, the global optimum is the same as the one above.

Case 14. If $c_{d}<\left(\left(p+c_{d}\right) / 2\right)-(\beta k d /(2(1-\beta)))<k b+c_{d}$ and $\left(\left(w_{r}+c_{d}\right) / 2\right)<k b+c_{d}<\left(\left(w_{r}-(1-\beta) p\right) / \beta\right)$, the analysis is shown in Figure 16.
We can see that the global optimum is $w_{u}^{*}=$ $\left(\left(p+c_{d}\right) / 2\right)-(\beta k d /(2(1-\beta)))$ and $q_{u}^{*}=b$, and the optimal profit is $\Pi_{b}^{D}\left(w_{u}^{*}, q_{u}^{*}\right)=(1-\beta) / k\left(\left(\left(p+c_{d}\right) / 2\right)-(\beta k d /(2(1-\right.$ $\beta)))^{2}-\left((1-\beta) p c_{d} / k\right)+\beta p b$.

Case 15. If $c_{d}<\left(\left(p+c_{d}\right) / 2\right)-(\beta k d /(2(1-\beta)))<k b+c_{d}<$ $\left(\left(w_{r}+c_{d}\right) / 2\right)$ and $\left(\left(w_{r}-(1-\beta) p\right) / \beta\right) \geq k b+c_{d}$, the analysis is shown in Figure 17.

The solution is the same as the one above.

Case 16. If $c_{d}<\left(\left(w_{r}+c_{d}\right) / 2\right)<k b+c_{d} \leq\left(\left(p+c_{d}\right) / 2\right)-(\beta k d /$ $(2(1-\beta)))$ and $\left(\left(w_{r}-(1-\beta) p\right) / \beta\right) \geq k b+c_{d}$, the analysis is shown in Figure 18.

As we can see, the global optimum is $w_{u}^{*}=k b+c_{d}$ and $q_{u}^{*}=b$, and the optimal profit is $\Pi_{b}^{D}\left(w_{u}^{*}, q_{u}^{*}\right)=$ $\left(p-c_{d}\right) b-k b^{2}$. 


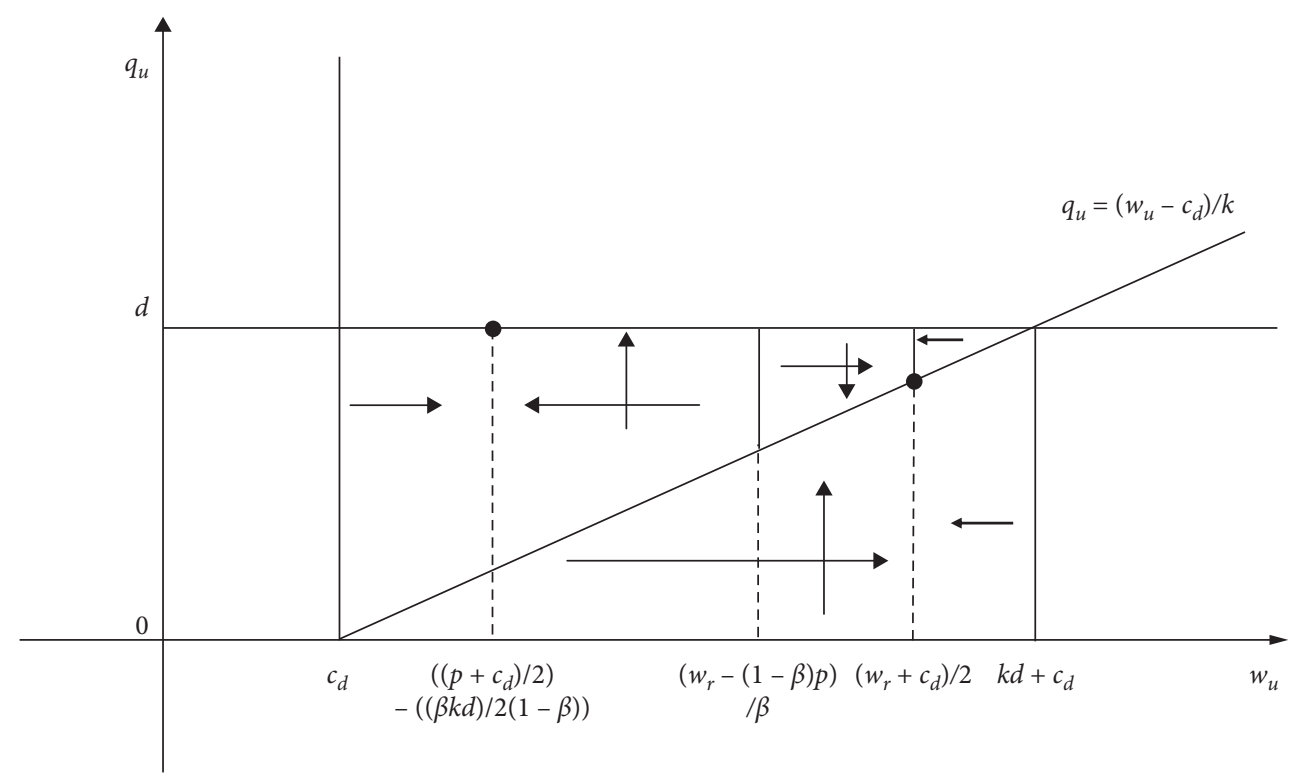

Figure 9: Case 7: $c_{d} \leq\left(\left(p+c_{d}\right) / 2\right)-(\beta k d /(2(1-\beta)))<\left(\left(w_{r}-(1-\beta) p\right) / \beta\right)<\left(\left(w_{r}+c_{d}\right) / 2\right) \leq k b+c_{d}$.

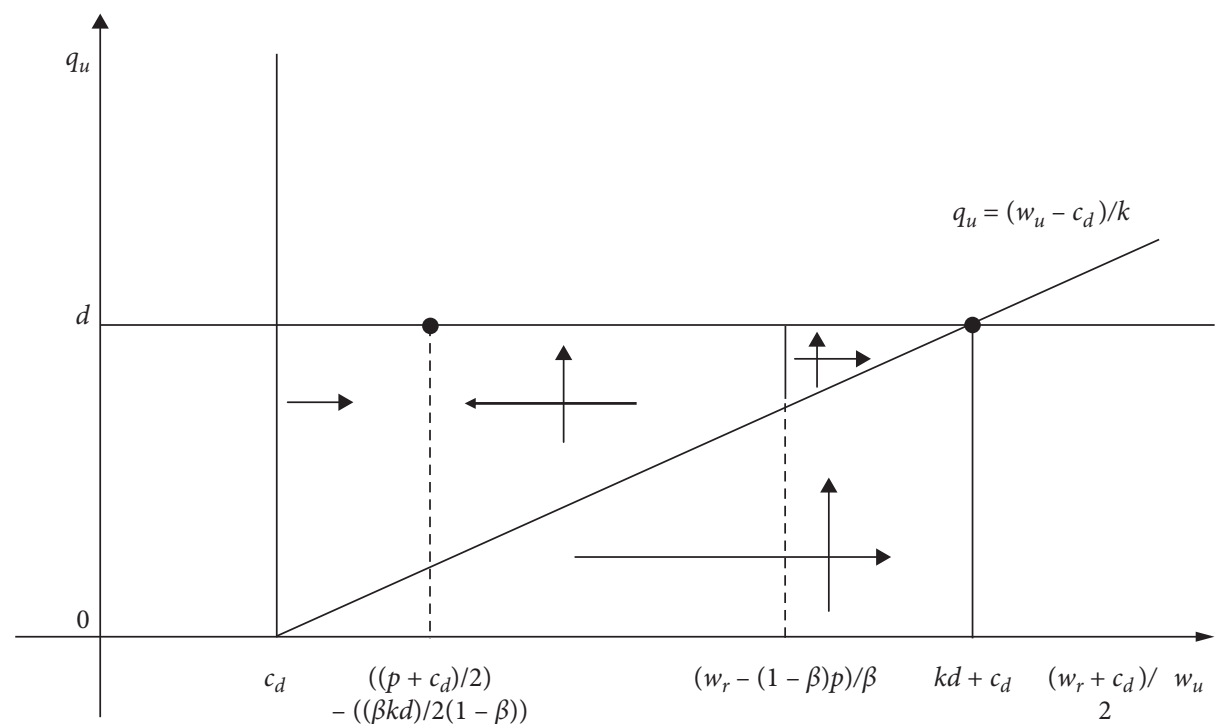

FiguRe 10: Case 8: $c_{d} \leq\left(\left(p+c_{d}\right) / 2\right)-(\beta k d /(2(1-\beta)))<\left(\left(w_{r}-(1-\beta) p\right) / \beta\right)<k b+c_{d} \leq\left(\left(w_{r}+c_{d}\right) / 2\right)$.

Case 17. If $\left(\left(w_{r}+c_{d}\right) / 2\right) \geq k b+c_{d}, \quad\left(\left(p+c_{d}\right) / 2\right)-(\beta k d /(2$ $(1-\beta))) \geq k b+c_{d}$, and $\left(\left(w_{r}-(1-\beta) p\right) / \beta\right) \geq k b+c_{d}$, the analysis is shown in Figure 19.

The solution is the same with the one above.

According to our analysis, we come to the conclusions which are summarized in Proposition 3.

Proposition 3. In all, the optimal strategy of the buyer might be divided into six different scenarios as follows:

(i) $w_{u}^{*}=\left(\left(w_{r}+c_{d}\right) / 2\right)$ and $q_{u}^{*}=\left(\left(w_{r}-c_{d}\right) / 2 k\right)$ if

(1) $\left(\left(w_{r}-(1-\beta) p\right) / \beta\right)<c_{d}$ and $\left(\left(w_{r}+c_{d}\right) / 2\right) \leq$ $k b+c_{d}$ or $(2)\left(\left(p+c_{d}\right) / 2\right)-(\beta k d /(2(1-\beta)))<c_{d}$ $\leq\left(\left(w_{r}-(1-\beta) p\right) / \beta\right)<\left(\left(w_{r}+c_{d}\right) / 2\right)<k b+c_{d}$ and $\prod_{b}^{D}\left(\left(w_{r}+c_{d}\right) / 2, \quad\left(w_{r}-c_{d}\right) / 2 k\right) \geq \prod_{b}^{D}\left(c_{d}, b\right)$ or (3) $c_{d} \leq\left(\left(p+c_{d}\right) / 2\right)-(\beta k d /(2(1-\beta)))<\left(\left(w_{r}-(1-\beta)\right.\right.$ $p) / \beta), \quad\left(\left(w_{r}-(1-\beta) p\right) / \beta\right)<\left(\left(w_{r}+c_{d}\right) / 2\right)<k b+c_{d}$, $\prod_{b}^{D}\left(\left(w_{r}+c_{d}\right) / 2,\left(w_{r}-c_{d}\right) / 2 k\right) \geq \prod_{b}^{D}\left(\left(p+c_{d}\right)\right.$

$/ 2-(\beta k b / 2(1-\beta)), b)$, or (4) $c_{d} \leq\left(w_{r}-(1-\beta) p\right) /$

$\beta \leq\left(w_{r}+c_{d}\right) / 2<k b+c_{d}$ and $\left(p+c_{d}\right) / 2-(\beta k b / 2$ $(1-\beta)) \geq\left(w_{r}-(1-\beta) p\right) / \beta$.

(ii) $w_{u}^{*}=k b+c_{d}$ and $q_{u}^{*}=b$ if

(1) $\left(\left(w_{r}-(1-\beta) p\right) / \beta\right)<c_{d}<k b+c_{d}<\left(\left(w_{r}+c_{d}\right) / 2\right)$ or $(2) c_{d} \leq\left(\left(p+c_{d}\right) / 2\right)-(\beta k d /(2(1-\beta)))<\left(\left(w_{r}-\right.\right.$ $(1-\beta) p) / \beta)<k b+c_{d} \leq\left(\left(w_{r}+c_{d}\right) / 2\right)$ and $\Pi_{b}^{D}(k b+$ $\left.c_{d}, b\right) \geq \Pi_{b}^{D}\left(\left(\left(p+c_{d}\right) / 2\right)-(\beta k d /(2(1-\beta))), b\right)$ or (3) $c_{d} \leq\left(\left(w_{r}-(1-\beta) p\right) / \beta\right) \leq\left(\left(p+c_{d}\right) / 2\right)-(\beta k d /$ $(2(1-\beta)))$ and $\left(\left(w_{r}+c_{d}\right) / 2\right) \geq k b+c_{d}$, or (4) $\left(\left(w_{r}-(1-\beta) p\right) / \beta\right) \geq k b+c_{d}$ and $\left(\left(p+c_{d}\right) / 2\right)-$ $(\beta k d /(2(1-\beta))) \geq k b+c_{d}$. 


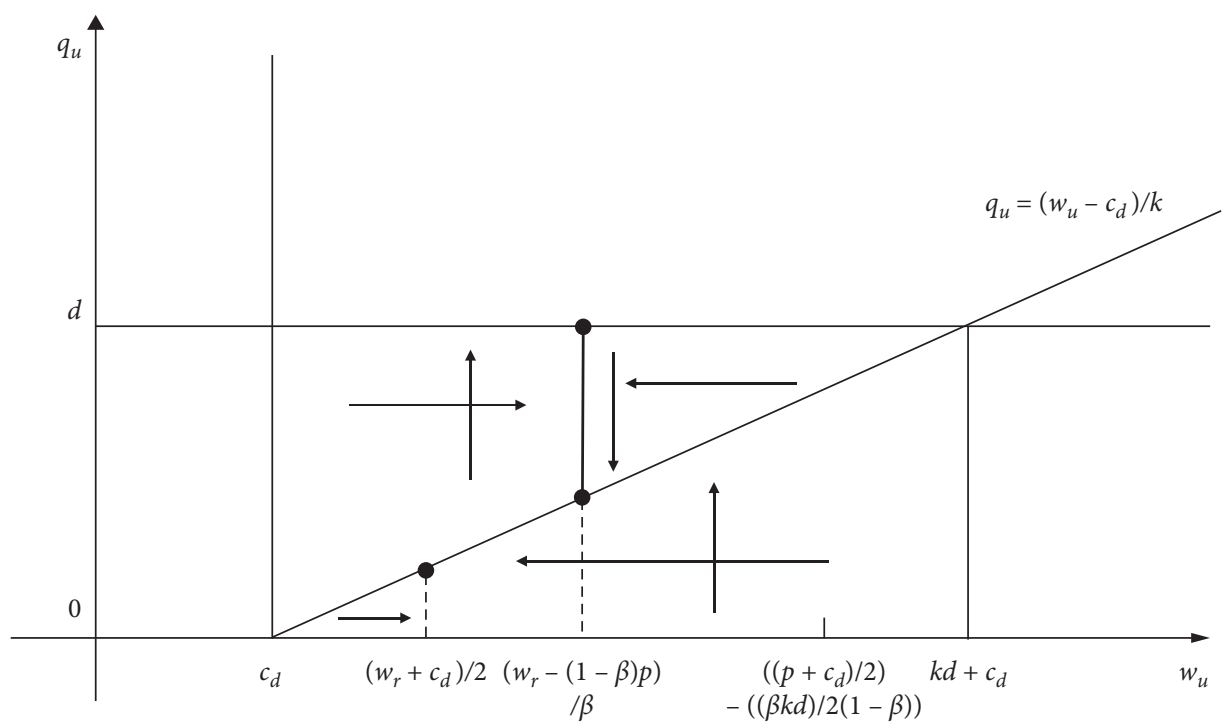

Figure 11: Case 9: $c_{d}<\left(\left(w_{r}+c_{d}\right) / 2\right)<\left(\left(w_{r}-(1-\beta) p\right) / \beta\right) \leq\left(\left(p+c_{d}\right) / 2\right)-(\beta k d /(2(1-\beta)))$ and $\left(\left(w_{r}-(1-\beta) p\right) / \beta\right)<k b+c_{d}$.

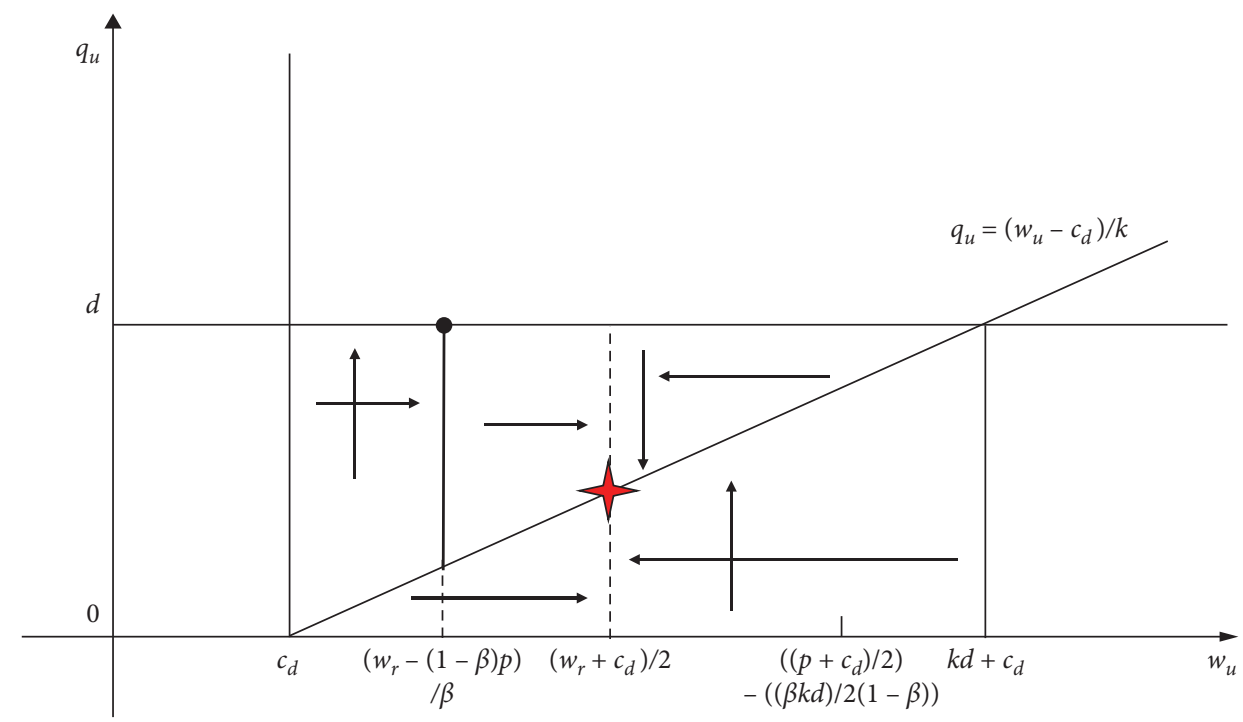

Figure 12: Case 10: $c_{d} \leq\left(\left(w_{r}-(1-\beta) p\right) / \beta\right) \leq\left(\left(w_{r}+c_{d}\right) / 2\right)<k b+c_{d}$ and $\left(\left(p+c_{d}\right) / 2\right)-(\beta k d /(2(1-\beta))) \geq\left(\left(w_{r}-(1-\beta) p\right) / \beta\right)$.

(iii) $w_{u}^{*}=c_{d}$ and $q_{u}^{*}=b$ if

(1) $\left(\left(p+c_{d}\right) / 2\right)-(\beta k d /(2(1-\beta)))<c_{d}<\left(\left(w_{r}+\right.\right.$ $\left.\left.c_{d}\right) / 2\right)<\left(\left(w_{r}-(1-\beta) p\right) / \beta\right)<k b+c_{d}$ or $(2)((p+$ $\left.\left.c_{d}\right) / 2\right)-(\beta k d /(2(1-\beta)))<c_{d} \leq\left(\left(w_{r}-(1-\beta) p\right)\right.$ $/ \beta)<\left(\left(w_{r}+c_{d}\right) / 2\right)<k b+c_{d}$ and $\Pi_{b}^{D}\left(\left(\left(w_{r}+\right.\right.\right.$ $\left.\left.\left.c_{d}\right) / 2\right),\left(\left(w_{r}-c_{d}\right) / 2 k\right)\right)<\Pi_{b}^{D}\left(c_{d}, b\right)$ or $(3) \quad((p+$ $\left.\left.c_{d}\right) / 2\right)-(\beta k d /(2(1-\beta)))<c_{d}<\left(\left(w_{r}-(1-\beta) p\right) /\right.$ $\beta)<k b+c_{d}<\left(\left(w_{r}+c_{d}\right) / 2\right)$, or $(4)\left(\left(p+c_{d}\right) / 2\right)-$ $(\beta k d /(2(1-\beta)))<c_{d}<k b+c_{d}<\left(\left(w_{r}-(1-\beta) p\right) / \beta\right)$.

(iv) $w_{u}^{*}=\left(\left(p+c_{d}\right) / 2\right)-(\beta k d /(2(1-\beta)))$ and $q_{u}^{*}=b$ if (1) $c_{d} \leq\left(\left(p+c_{d}\right) / 2\right)-(\beta k d /(2(1-\beta)))<\left(\left(w_{r}-\right.\right.$ $(1-\beta) p) / \beta)$ and $\left(\left(w_{r}+c_{d}\right) / 2\right) \leq\left(\left(w_{r}-(1-\beta) p\right) /\right.$ $\beta)<k b+c_{d} \quad$ or $\quad(2) \quad c_{d} \leq\left(\left(p+c_{d}\right) / 2\right)-(\beta k d /$ $(2(1-\beta)))<\left(\left(w_{r}-(1-\beta) p\right) / \beta\right), \quad\left(\left(w_{r}-(1-\right.\right.$ $\beta) p) / \beta)<\left(\left(w_{r}+c_{d}\right) / 2\right)<k b+c_{d}$, and $\Pi_{b}^{D}\left(\left(\left(w_{r}+\right.\right.\right.$ $\left.\left.\left.c_{d}\right) / 2\right),\left(\left(w_{r}-c_{d}\right) / 2 k\right)\right)<\Pi_{b}^{D}\left(\left(\left(p+c_{d}\right) / 2\right)-(\beta k d /\right.$ $(2(1-\beta))), b)$ or (3) $c_{d} \leq\left(\left(p+c_{d}\right) / 2\right)-(\beta k d /$ $(2(1-\beta)))<\left(\left(w_{r}-(1-\beta) p\right) / \beta\right)<k b+c_{d} \leq$ $\left(\left(w_{r}+c_{d}\right) / 2\right)$ and $\Pi_{b}^{D}\left(k b+c_{d}, b\right)<\Pi_{b}^{D} \quad(((p+$ $\left.\left.\left.c_{d}\right) / 2\right)-(\beta k d /(2(1-\beta))), b\right)$, or $(4) \quad c_{d} \leq((p+$ $\left.\left.c_{d}\right) / 2\right)-(\beta k d /(2(1-\beta)))<k b+c_{d} \leq\left(\left(w_{r}-(1-\right.\right.$ $\beta) p) / \beta$.

(v) $w_{u}^{*}=\left(\left(w_{r}-(1-\beta) p\right) / \beta\right)$ and $q_{u}^{*}=b$ if

$c_{d}<\quad\left(\left(w_{r}+c_{d}\right) / 2\right)<\left(\left(w_{r}-(1-\beta) p\right) / \beta\right) \leq((p+$ $\left.\left.c_{d}\right) / 2\right)-(\beta k d /(2(1-\beta))), \quad\left(\left(w_{r}-(1-\beta) p\right) / \beta\right)<$ $k b+c_{d}$, and $\Pi_{b}^{D}\left(\left(w_{r}-(1-\beta) p\right) / \beta, b\right) \geq \Pi_{b}^{D}\left(\left(\left(w_{r}-\right.\right.\right.$ $\left.(1-\beta) p) / \beta),\left(p-c_{d}\right) / k-\left(p-w_{r}\right) / \beta k\right)$.

(vi) $w_{u}^{*}=\left(\left(w_{r}-(1-\beta) p\right) / \beta\right)$ and $q_{u}^{*}=\left(\left(p-c_{d}\right) / k\right)-$ $\left(p-w_{r}\right) / \beta k$ if 


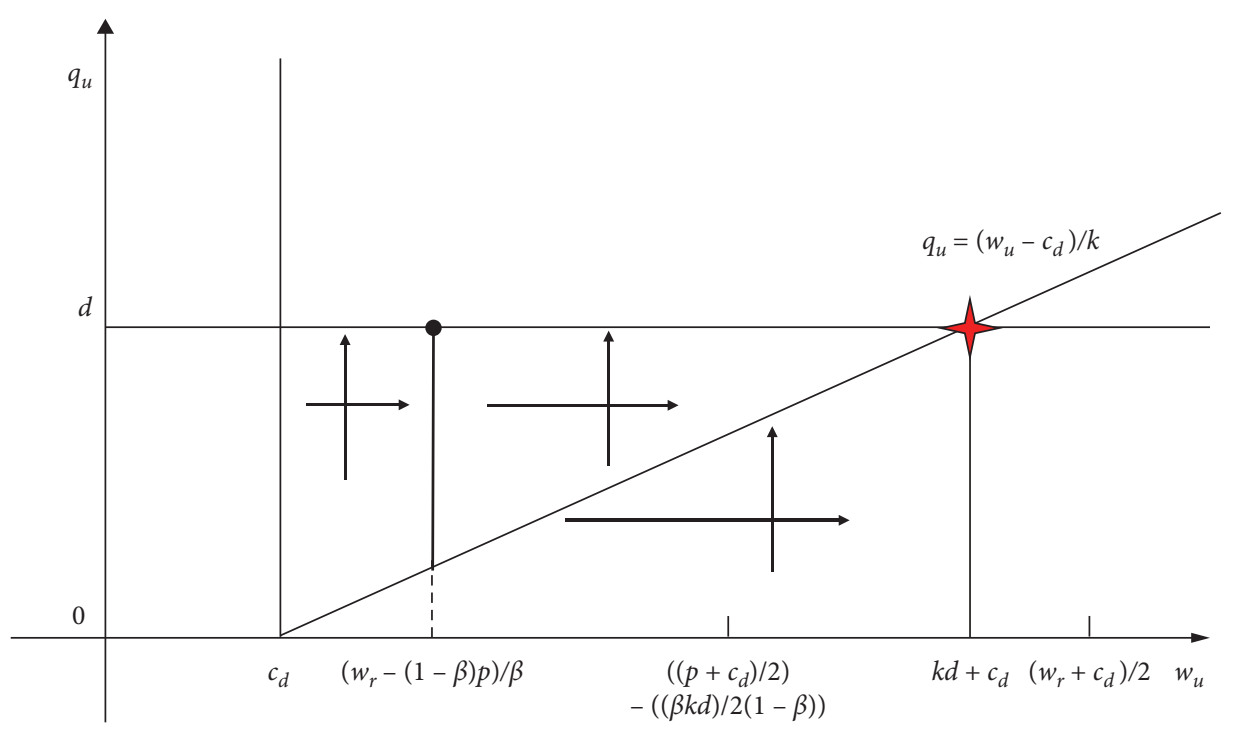

Figure 13: Case 11: $c_{d} \leq\left(\left(w_{r}-(1-\beta) p\right) / \beta\right) \leq\left(\left(p+c_{d}\right) / 2\right)-(\beta k d /(2(1-\beta)))$ and $\left(\left(w_{r}+c_{d}\right) / 2\right) \geq k b+c_{d}$.

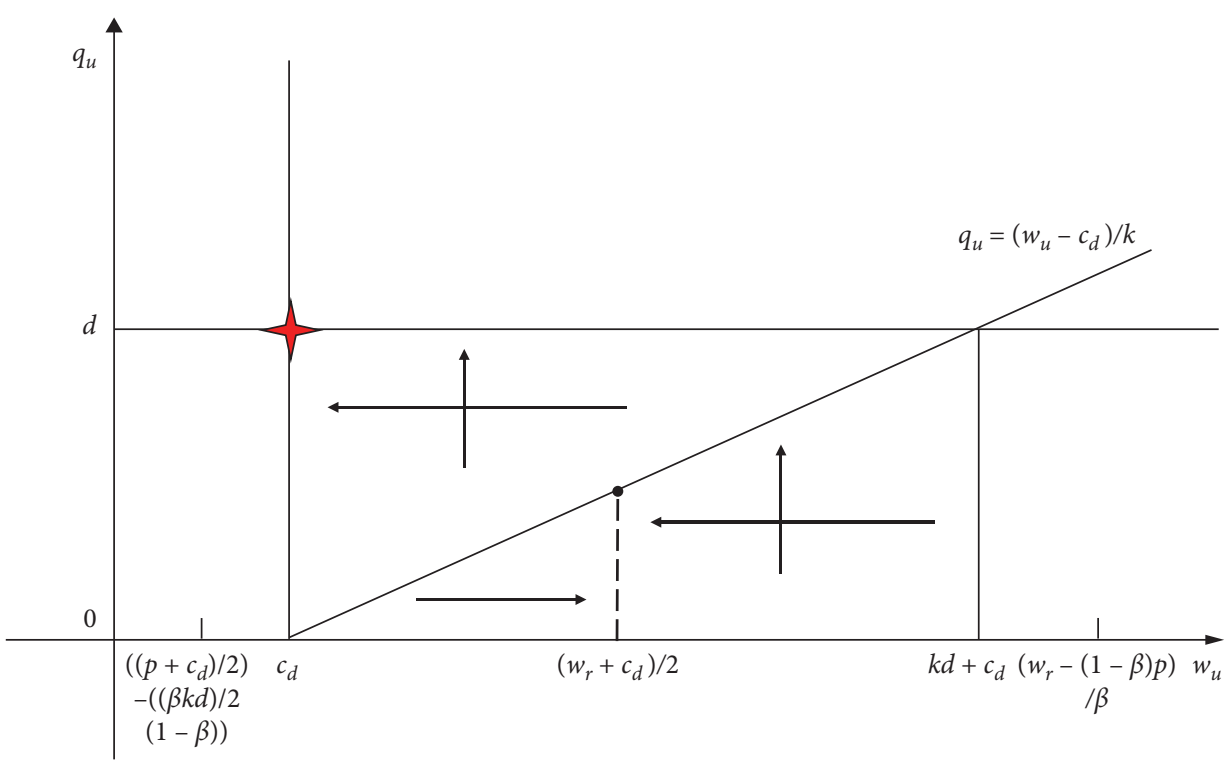

Figure 14: Case 12: $\left(\left(p+c_{d}\right) / 2\right)-(\beta k d /(2(1-\beta)))<c_{d}<\left(\left(w_{r}+c_{d}\right) / 2\right)<k b+c_{d}<\left(\left(w_{r}-(1-\beta) p\right) / \beta\right)$.

$c_{d}<\left(\left(w_{r}+c_{d}\right) / 2\right)<\left(\left(w_{r}-(1-\beta) p\right) / \beta\right) \leq((p+$ $\left.\left.c_{d}\right) / 2\right)-(\beta k d /(2(1-\beta))), \quad\left(\left(w_{r}-(1-\beta) p\right) / \beta\right)<$ $k b+c_{d}$, and $\Pi_{b}^{D}\left(\left(w_{r}-(1-\beta) p\right) / \beta, b\right)<\Pi_{b}^{D}\left(\left(\left(w_{r}-\right.\right.\right.$ $\left.(1-\beta) p) / \beta),\left(p-c_{d}\right) / k-\left(p-w_{r}\right) / \beta k\right)$.

Furthermore, from Proposition 3, we can obtain the optimal restoration effort of the unreliable supplier as shown in Proposition 4.

Proposition 4. Given the optimal contract provided by the buyer $\left(w_{u}^{*}, q_{u}^{*}\right)$, the optimal restoration effort exerted by the unreliable supplier is $e^{*}\left(w_{u}^{*}, q_{u}^{*}\right)=\min \left\{\left(\left(w_{u}^{*}-c_{d}\right) / k\right), q_{u}^{*}\right\}$.

\section{Numerical Study}

Since it is hard to obtain the closed forms of our decision variables, we conduct the following numerical analysis to generate some managerial insights. When the buyer orders only from the reliable supplier, the case would be easy to understand. In this way, we conduct numerical analyses for the case when the buyer orders only from the unreliable supplier and the case when the buyer adopts supply diversification strategy. Among all parameters, the probability without disruption $\beta$ and the unit production cost after disruption $c_{d}$ would be the two most important factors that affect the buyer's ordering strategy. Thus, we first assign the 


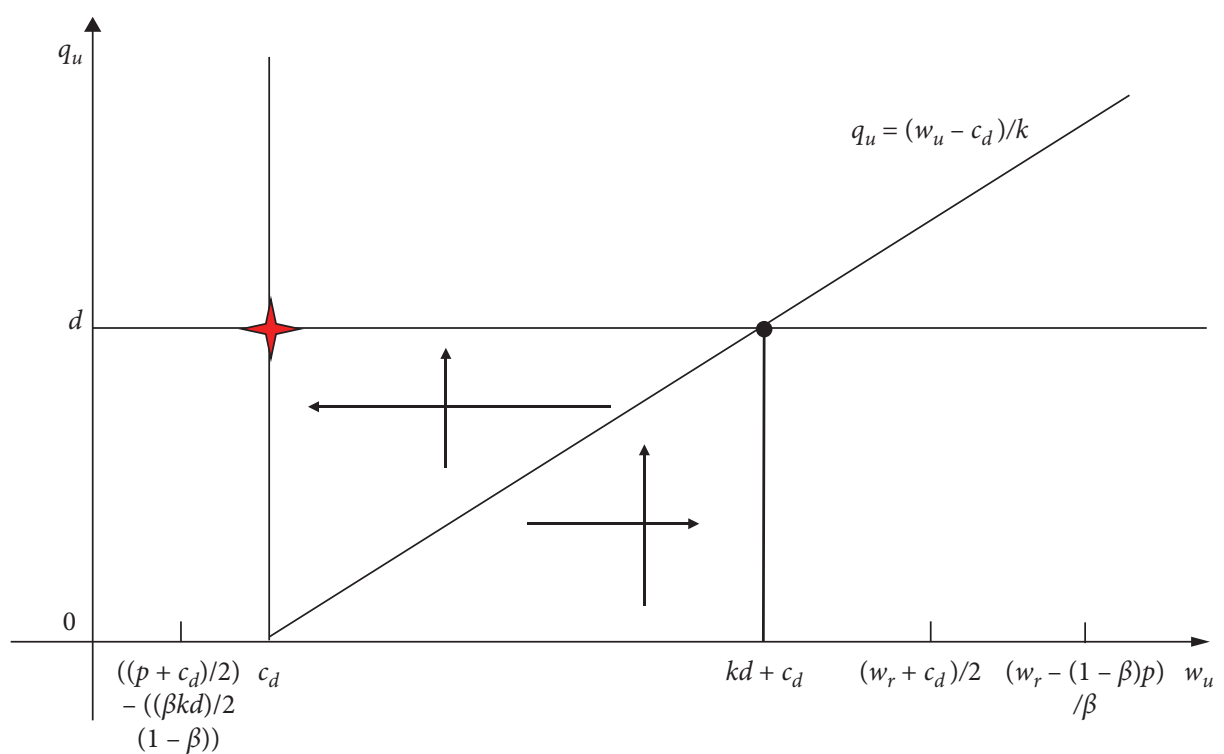

Figure 15: Case 13: $\left(\left(p+c_{d}\right) / 2\right)-(\beta k d /(2(1-\beta)))<c_{d}<k b+c_{d}<\left(\left(w_{r}+c_{d}\right) / 2\right)$ and $\left(\left(w_{r}-(1-\beta) p\right) / \beta\right) \geq k b+c_{d}$.

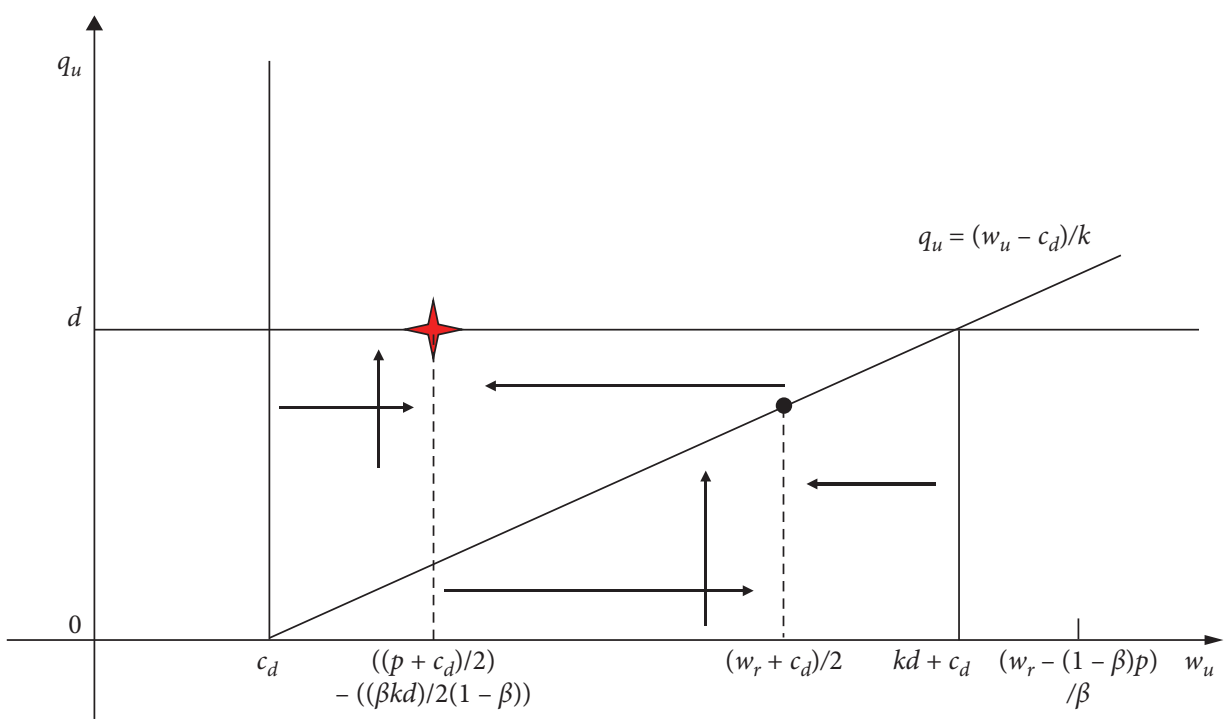

FiguRe 16: Case 14: $c_{d}<\left(\left(p+c_{d}\right) / 2\right)-(\beta k d /(2(1-\beta)))<k b+c_{d}$ and $\left(\left(w_{r}+c_{d}\right) / 2\right)<k b+c_{d}<\left(\left(w_{r}-(1-\beta) p\right) / \beta\right)$.

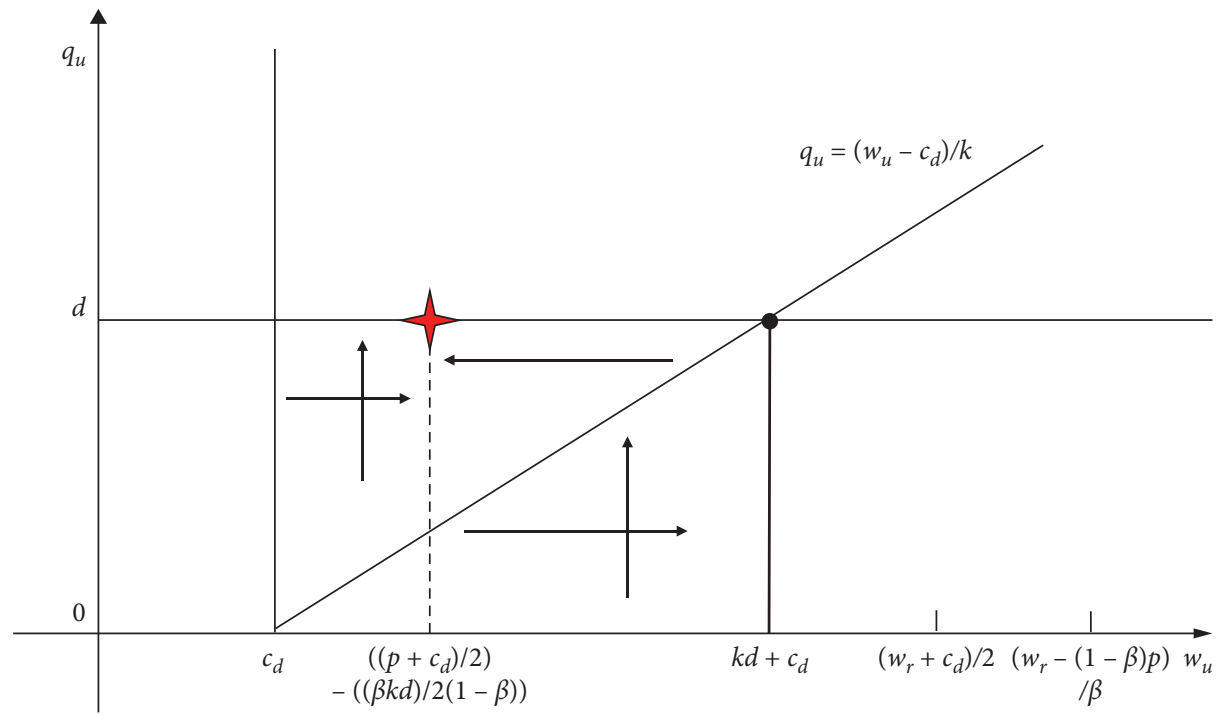

Figure 17: Case 15: $c_{d}<\left(\left(p+c_{d}\right) / 2\right)-(\beta k d /(2(1-\beta)))<k b+c_{d}<\left(\left(w_{r}+c_{d}\right) / 2\right)$ and $\left(\left(w_{r}-(1-\beta) p\right) / \beta\right) \geq k b+c_{d}$. 


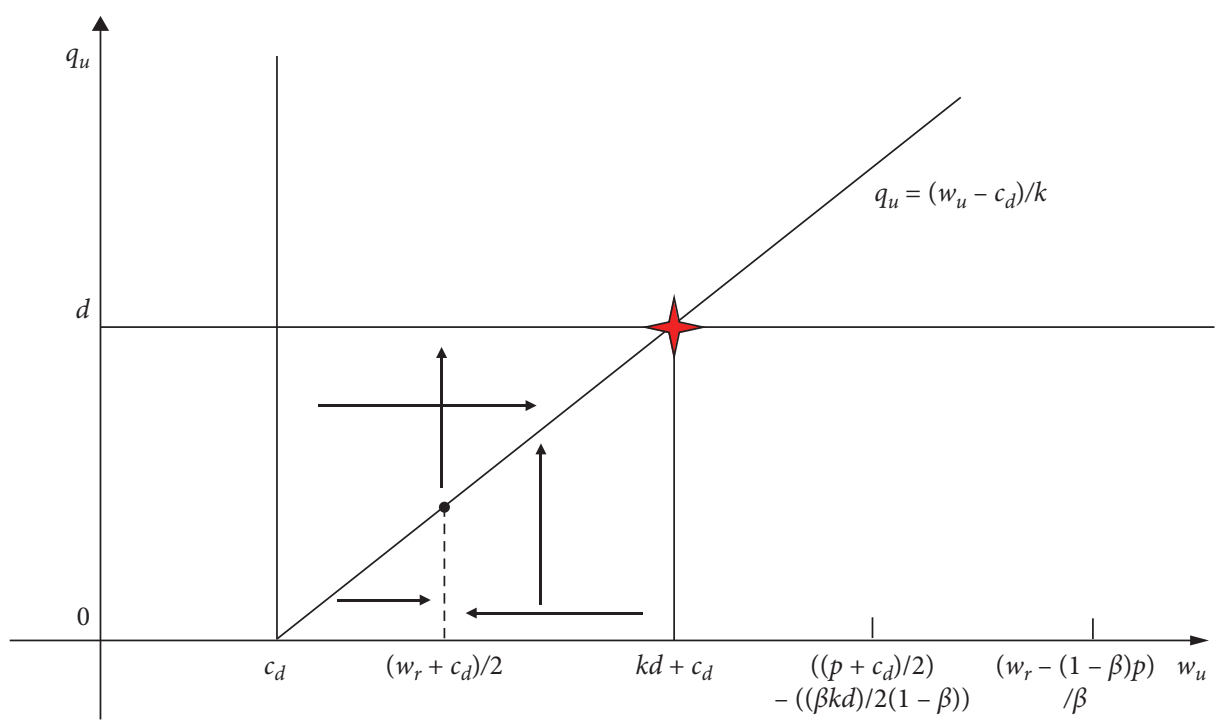

Figure 18: Case 16: $c_{d}<\left(\left(w_{r}+c_{d}\right) / 2\right)<k b+c_{d} \leq\left(\left(p+c_{d}\right) / 2\right)-(\beta k d /(2(1-\beta)))$ and $\left(w_{r}-(1-\beta) p\right) / \beta \geq k b+c_{d}$.

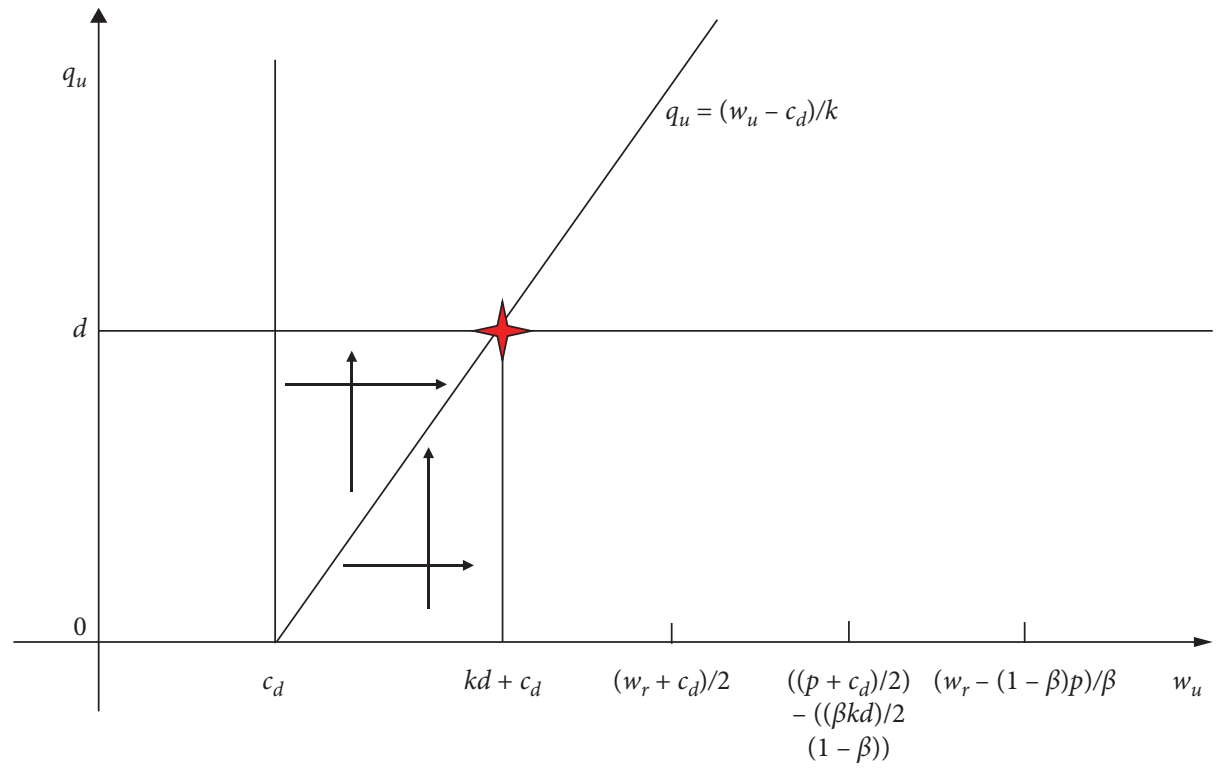

Figure 19: Case 17: $\left(\left(w_{r}+c_{d}\right) / 2\right) \geq k b+c_{d},\left(\left(p+c_{d}\right) / 2\right)-(\beta k d /(2(1-\beta))) \geq k b+c_{d}$, and $\left(\left(w_{r}-(1-\beta) p\right) / \beta\right) \geq k b+c_{d}$.

following values to other parameters: $d=1, k=1 / 2, p=1$, $w_{r}=1 / 2$.

5.1. Ordering Only from Unreliable Supplier. When ordering only from the unreliable supplier, the buyer has to offer a contract $\left(q_{u}, w_{u}\right)$ to the unreliable supplier. Through equilibrium analysis, it is easy to obtain $q_{u}^{*}=d$. Here, we conduct a numerical study on $w_{u}^{*}$ to show its property based on Proposition 2. The results are shown in Figure 20.

From Figure 20, we find that the wholesale price for the unreliable supplier $\left(w_{u}^{*}\right)$ increases with the unit production cost after disruption $\left(c_{d}\right)$ and decreases with the probability without disruption $(\beta)$. The interesting observation is that, if $\beta$ is high enough, $w_{u}^{*}$ would always be equal to $c_{d}$ (see Figure 20(c)); otherwise, there exists a threshold of $c_{d}$ where $w_{u}^{*}$ would be higher when $\beta$ is relatively low below this threshold (see Figures 20(a) and 20(b)). This reflects the fact that when the disruption is easy to occur, the buyer would provide a more favorable contract with a higher wholesale price to encourage the unreliable supplier to exert effort on restoring capacity.

5.2. Supply Diversification Strategy. In this part, we conduct a numerical study when the buyer adopts supply diversification strategy. From equilibrium analysis, we know that the buyer would always order the quantity that equals the deterministic demand from both retailers. Thus, the order quantity from the reliable supplier $q_{r}$ would be equal to $d-q_{u}$. Here, we concentrate on the contract $\left(q_{u}, w_{u}\right)$ provided to the unreliable supplier. The results are shown in Figures 21 and 22. 


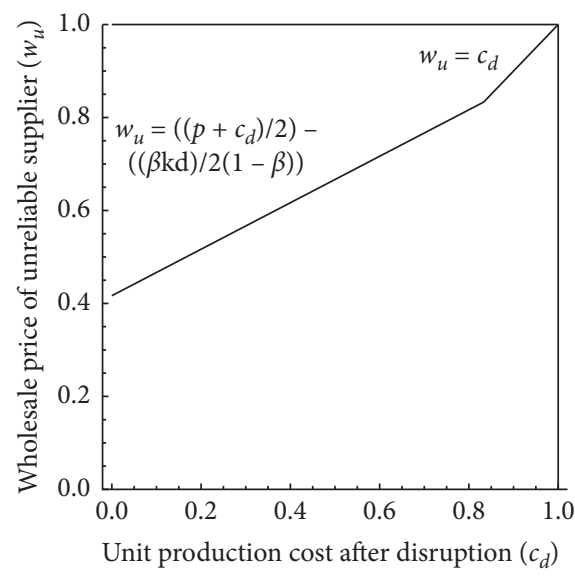

(a)

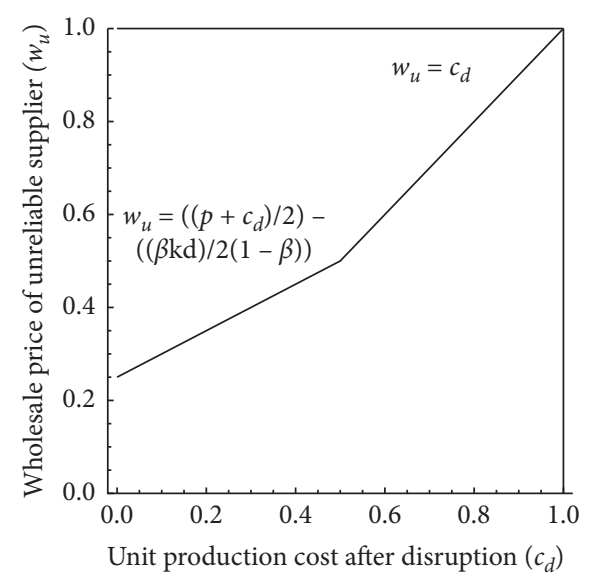

(b)

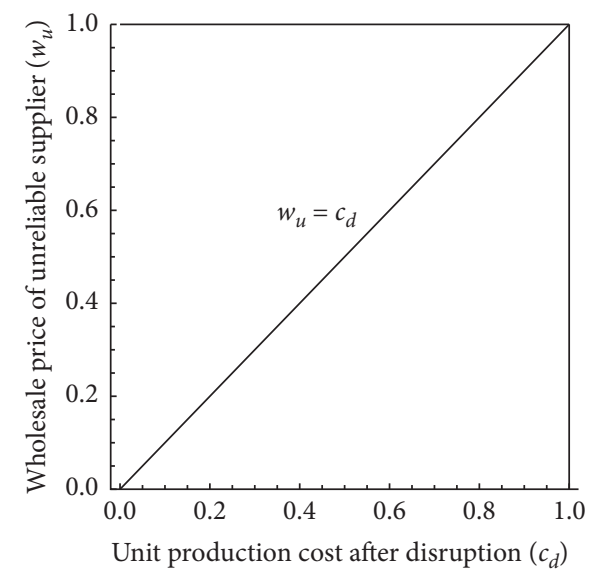

(c)

FIGURE 20: Optimal wholesale price $w_{u}^{*}$ for unreliable supplier in the case of ordering only from the unreliable supplier.

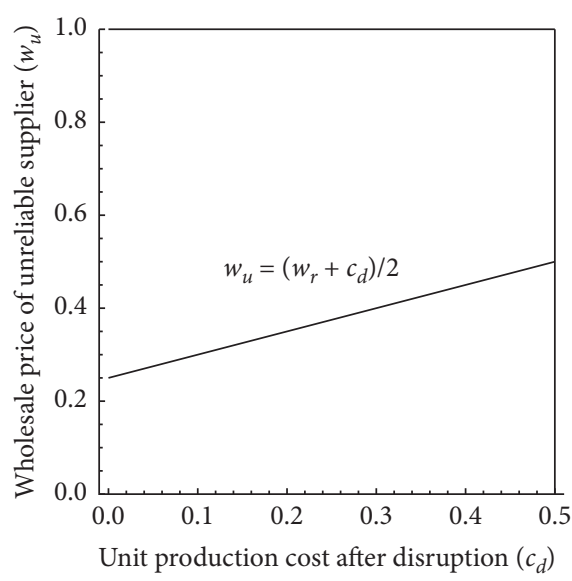

(a)

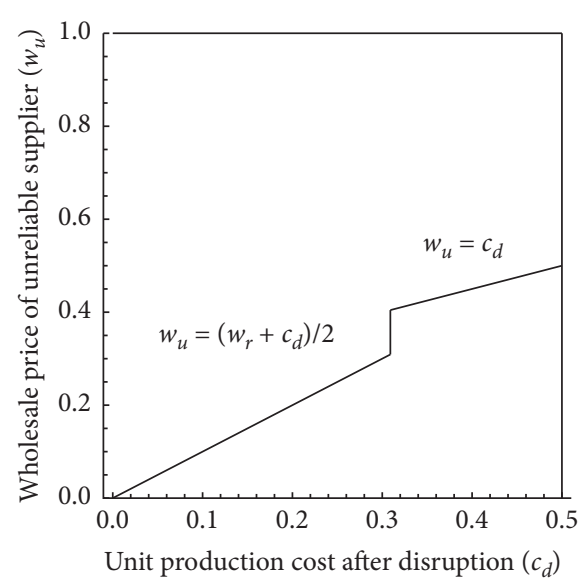

(b)

Figure 21: Continued. 


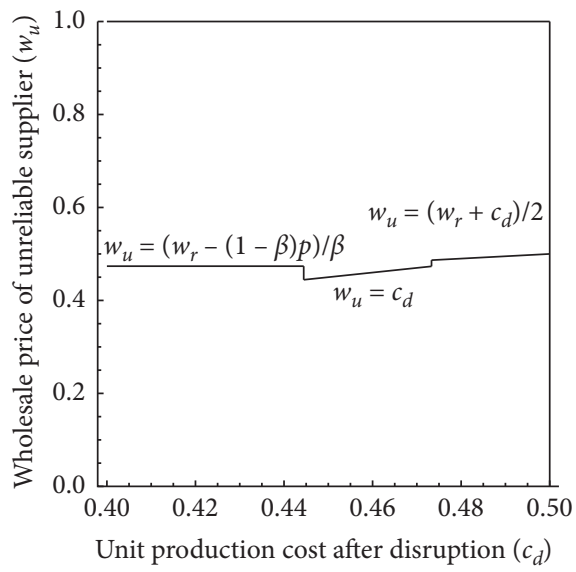

(c)

FIGURE 21: Optimal wholesale price $w_{u}^{*}$ for unreliable supplier in the case of supply diversification strategy.

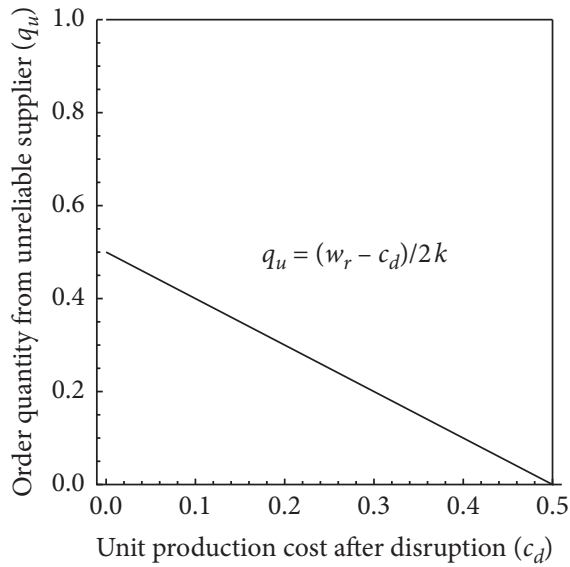

(a)

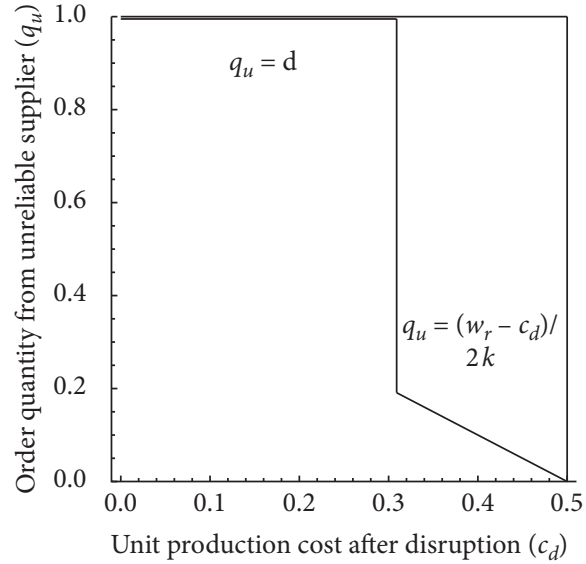

(b)

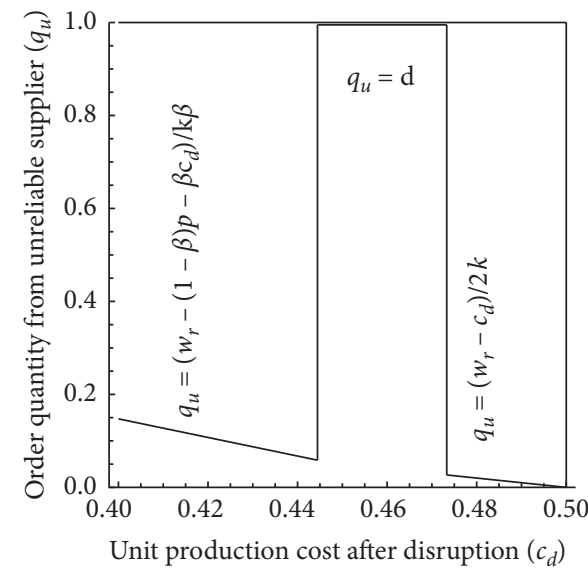

(c)

FIgURE 22: Optimal order quantity $q_{u}^{*}$ for unreliable supplier in the case of supply diversification strategy. 
From Figure 21, we find that the wholesale price for the unreliable supplier $\left(w_{u}^{*}\right)$ is a nondecreasing function of the unit production cost after disruption $\left(c_{d}\right)$, while the effect of the probability without disruption $(\beta)$ on the wholesale price for the unreliable supplier $\left(w_{u}^{*}\right)$ is not consistent. Specifically, if $\beta$ is relatively low, $w_{u}^{*}$ increases with $c_{d}$ at a constant rate (see Figure 21(a)). If $\beta$ is intermediate, there would be a sudden increase in $w_{u}^{*}$ when $c_{d}$ reaches a certain threshold, but the increase rate would be lower since then (see Figure 21(b)). If $\beta$ is high enough, $c_{d}$ has no effect on $w_{u}^{*}$ when $c_{d}$ is relatively low and would have a larger effect on $w_{u}^{*}$ when $c_{d}$ is intermediate than when $c_{d}$ is high enough (see Figure 21(c)).

This shows that if the disruption is easy to happen, the buyer would trade off between the wholesale price from the reliable supplier $\left(w_{r}\right)$ and the unit production cost after disruption $\left(c_{d}\right)$ to offer a good wholesale price to the unreliable supplier, encouraging it to restore capacity when the disruption happens. However, with the increase of the unit production cost after disruption $\left(c_{d}\right)$, the buyer would rely more on the reliable supplier than on the unreliable one by reducing the order quantity from the unreliable supplier $\left(q_{u}^{*}\right)$ (see Figure 22(a)). If the probability without disruption is neither too low nor too high, the buyer would tend to encourage the unreliable supplier to guarantee supply and source all the demand from the unreliable one when $c_{d}$ is below a threshold but would only offer a $w_{u}^{*}$ that just equals $c_{d}$ when $c_{d}$ is very high (see Figure 22(b)). If the disruption seldom happens, sourcing from the unreliable supplier would be the best choice for the buyer especially when $c_{d}$ is relatively low. Under this circumstance, the buyer would choose a wholesale price that jointly considered the retail price $(p)$, the probability without disruption $(\beta)$, and the wholesale price from the reliable supplier $\left(w_{r}\right)$. However, when $c_{d}$ is intermediate, the buyer would offer a contract that sources all the demand from the unreliable supplier with a wholesale price that equals the unit production cost after disruption.

\section{Conclusion}

Various human or environmental factors such as natural disasters and political disputes can cause production disruption, which negatively affects the buyer's procurement process and thus causes financial loss. This paper studies a noncooperative model that consists of two suppliers and one buyer. Since the buyer is a large-scale company with widespread reputation like Walmart and Apple, it chooses between the two types of suppliers: one is cheap but unreliable and the other is expensive but reliable and it offers contracts to them. Jointly considering the contract provided by the buyer and the cost of restoring capacity, the unreliable supplier may make efforts to rebuilt its capacity when a disruption occurs. The optimal procurement strategy is supply diversification strategy that is ordering from both suppliers with different proportions. This paper provides the contract offered by the buyer with optimal wholesale price and order quantity to the unreliable supplier in different scenarios. The main contributions to the literature are twofold. On the one hand, the proposed model characterizes the real situation of big retailers who have the power towards pricing when wholesale products from small suppliers and the contract offered by the buyer can affect the unreliable supplier's optimal strategy on its restoration effort when a disruption occurs. On the other hand, the results generate the optimal contract containing the wholesale price and order quantity provided by the buyer to the unreliable supplier under different circumstances, which can be used by managers to design the procurement contract facing different types of suppliers and different environment. There are some possible ways to extend this research. First, the proposed model assumes that the market demand is deterministic, which might be extended to stochastic demand. Second, the restoration cost of the unreliable supplier is assumed to be deterministic, which is proportional to the restoration effort, and it is worthwhile to define the cost as other distribution functions of the restoration effort. At last, by assuming that the wholesale price for the reliable supplier is exogenously given and the total order quantity equals the demand, the proposed model mainly designs the contract for the unreliable supplier; it might be interesting to codetermine the contracts offered to both suppliers by relaxing the above assumptions.

\section{Data Availability}

No data were used to support this study.

\section{Conflicts of Interest}

The authors declare that there are no conflicts of interest regarding the publication of this paper.

\section{Acknowledgments}

This research was supported by the Fundamental Research Funds for the Central Universities (Grant no. JBK2001067).

\section{References}

[1] Y. Zhou, J. Feng, J. Wei, and X. Sun, "Pricing decisions of a dual-channel supply chain considering supply disruption risk," Mathematical Problems in Engineering, vol. 2018, Article ID 6841519, 16 pages, 2017.

[2] A. Latour, "A fire in Albuquerque sparks crisis for European cell-phone giants," The Wall Street Journal, 2001.

[3] A. J. Vakharia and A. Yenipazarli, "Managing supply chain disruptions," Foundations and Trends in Technology, Information and Operations Management, vol. 2, no. 4, pp. 243325, 2008.

[4] L. V. Snyder, Z. Atan, P. Peng, Y. Rong, A. J. Schmitt, and B. Sinsoysal, "OR/MS models for supply chain disruptions: a review," IIE Transactions, vol. 48, no. 2, pp. 89-109, 2016.

[5] D. Ivanov, A. Dolgui, B. Sokolov, and M. Ivanova, "Literature review on disruption recovery in the supply chain," International Journal of Production Research, vol. 55, no. 20, pp. 6158-6174, 2017.

[6] R. Anupindi and R. Akella, "Diversification under supply uncertainty," Management Science, vol. 39, no. 8, pp. 944-963, 1993. 
[7] M. Dada, N. C. Petruzzi, and L. B. Schwarz, A Nesvendor Model with Unreliable Suppliers, University of Illinois at Urbana-Champaign, Champaign, IL, USA, 2003.

[8] H. Gurnani, R. Akella, and J. Lehoczky, "Optimal order policies in assembly systems with random demand and random supplier delivery," IIE Transactions, vol. 28, no. 11, pp. 865-878, 1996.

[9] S. Liu, K. C. So, and F. Zhang, "Effect of supply reliability in a retail setting with joint marketing and inventory decisions," Manufacturing \& Service Operations Management, vol. 12, no. 1, pp. 19-32, 2010.

[10] Y. Wang, W. Gilland, and B. Tomlin, "Mitigating supply risk: Dual sourcing or process improvement?" Manufacturing \& Service Operations Management, vol. 12, no. 3, pp. 489-510, 2010.

[11] W. Wang, K. Xue, and X. Sun, "Cost sharing in the prevention of supply chain disruption," Mathematical Problems in Engineering, vol. 2017, Article ID 7843465, 8 pages, 2017.

[12] B. Tomlin, "On the value of mitigation and contingency strategies for managing supply chain disruption risks," Management Science, vol. 52, no. 5, pp. 639-657, 2006.

[13] X. Hu, H. Gurnani, and L. Wang, "Managing risk of supply disruptions: incentives for capacity restoration," Production and Operations Management, vol. 22, no. 1, pp. 137-150, 2013.

[14] Z. Chen, J. Li, Z. Liu, and Z. Zheng, "Incentive contracts for capacity restoration under risk of supply disruption," IEEE Transactions on Engineering Management, vol. 66, no. 4, pp. 746-762, 2019.

[15] V. Gupta, B. He, and S. P. Sethi, "Contingent sourcing under supply disruption and competition," International Journal of Production Research, vol. 53, no. 10, pp. 3006-3027, 2015.

[16] P. Ray and M. Jenamani, "Sourcing decision under disruption risk with supply and demand uncertainty: a newsvendor approach," Annual Operation Research, vol. 237, no. 1-2, pp. 237-262, 2016.

[17] S. Y. Tang, H. Gurnani, and D. Gupta, "Managing disruptions in decentralized supply chains with endogenous supply process reliability," Production and Operations Management, vol. 23, no. 7, pp. 1198-1211, 2014.

[18] W. C. Tsai, "A dynamic sourcing strategy considering supply disruption risks," International Journal of Production Research, vol. 54, no. 7, pp. 2170-2184, 2016.

[19] E. Ang, D. A. Iancu, and R. Swinney, "Disruption risk and optimal sourcing in multitier supply networks," Management Science, vol. 63, no. 8, pp. 2397-2419, 2016.

[20] J. Li, X. Liu, J. Wu, and F. Yang, "Coordination of supply chain with a dominant retailer under demand disruptions," Mathematical Problems in Engineering, vol. 2014, Article ID 854681, 10 pages, 2014

[21] T. Shu, F. Yang, S. Chen, S. Wang, K. K. Lai, and L. Gan, "Contract coordination in dual sourcing supply chain under supply disruption risk," Mathematical Problems in Engineering, vol. 2015, no. 10, Article ID 473212, 2015.

[22] H. Zhang, Y. Liu, and J. Huang, "Supply chain coordination contracts under double sided disruptions simultaneously," Mathematical Problems in Engineering, vol. 2015, Article ID 812043, 9 pages, 2015.

[23] T. Sawik, "Stochastic versus deterministic approach to coordinated supply chain scheduling," Mathematical Problems in Engineering, vol. 2017, Article ID 3460721, 15 pages, 2017.

[24] C. S. Tang, "Robust strategies for mitigating supply chain disruptions," International Journal of Logistics Research and Applications, vol. 9, no. 1, pp. 33-45, 2006.
[25] S. Chopra and M. Sodhi, "Reducing the risk of supply chain disruptions," MIT Sloan Management Review, vol. 55, no. 3, pp. 72-80, 2014.

[26] J. He, F. Alavifard, D. Ivanov, and H. Jahani, "A real-option approach to mitigate disruption risk in the supply chain," Omega, vol. 88, pp. 133-149, 2019.

[27] T. A. Roemer and R. Ahmadi, "Concurrent crashing and overlapping in product development," Operations Research, vol. 52, no. 4, pp. 606-622, 2004.

[28] C. J. Corbeet, D. Zhou, and C. S. Tang, "Deigning supply contracts: contract type and information asymmetry," Management Science, vol. 51, no. 1, pp. 30-44, 2004.

[29] P. S. Desai and K. Srinivasan, "Demand signalling under unobservable effort in franchising: linear and nonlinear price contracts," Management Science, vol. 41, no. 10, pp. 1608-1623, 1995.

[30] H. S. Heese and J. M. Swaminathan, "Product line design with component commonality and cost-reduction effort," Manufacturing \& Service Operations Management, vol. 8, no. 2, pp. 206-219, 2006. 